IZA DP No. 6733

Intangible Capital and Growth in Advanced Economies: Measurement Methods and Comparative Results

Carol Corrado

Jonathan Haskel

Cecilia Jona-Lasinio

Massimiliano lommi

July 2012 


\title{
Intangible Capital and Growth in Advanced Economies: Measurement Methods and Comparative Results
}

\author{
Carol Corrado \\ The Conference Board, New York \\ Jonathan Haskel \\ Imperial College Business School, CEPR and IZA
}

Cecilia Jona-Lasinio

ISTAT and LLEE, Rome

Massimiliano lommi

ISTAT and LLEE, Rome
Discussion Paper No. 6733
July 2012

IZA
P.O. Box 7240
53072 Bonn
Germany

Phone: +49-228-3894-0

Fax: +49-228-3894-180

E-mail: iza@iza.org

\begin{abstract}
Any opinions expressed here are those of the author(s) and not those of IZA. Research published in this series may include views on policy, but the institute itself takes no institutional policy positions.

The Institute for the Study of Labor (IZA) in Bonn is a local and virtual international research center and a place of communication between science, politics and business. IZA is an independent nonprofit organization supported by Deutsche Post Foundation. The center is associated with the University of Bonn and offers a stimulating research environment through its international network, workshops and conferences, data service, project support, research visits and doctoral program. IZA engages in (i) original and internationally competitive research in all fields of labor economics, (ii) development of policy concepts, and (iii) dissemination of research results and concepts to the interested public.
\end{abstract}

IZA Discussion Papers often represent preliminary work and are circulated to encourage discussion. Citation of such a paper should account for its provisional character. A revised version may be available directly from the author. 
IZA Discussion Paper No. 6733

July 2012

\section{ABSTRACT}

\section{Intangible Capital and Growth in Advanced Economies: Measurement Methods and Comparative Results*}

We present a harmonized data set on intangible investment for a number of EU countries and an analysis of growth.

JEL Classification: $\quad 047$

Keywords: growth, intangible investment

Corresponding author:

Jonathan Haskel

Imperial College Business School

Tanaka Building, Room 296

South Kensington Campus

London SW7 2AZ

United Kingdom

E-mail: j.haskel@ic.ac.uk

\footnotetext{
* Paper originally prepared for a workshop sponsored by the European Commission, FP7 SSH PolicyScience Dialogue: Joint database on intangibles for European policy making - Data from INNODRIVE, COINVEST and the Conference Board, Brussels, Belgium, December 14, 2011. We thank our partners in these projects and Alessandra Colecchia of the OECD for comments on an earlier draft. Estimates described in this paper are available at http://www.INTAN-Invest.net. The views expressed in the article are those of the authors and do not involve the responsibility of the Italian Statistical Institute.
} 


\title{
Intangible Capital and Growth in Advanced Economies: Measurement and Comparative Results
}

\author{
Carol Corrado, Jonathan Haskel, Cecilia Jona-Lasinio and Massimiliano Iommi \\ "We will be more likely to promote innovative activity if \\ we are able to measure it more effectively and document its role in economic growth" \\ U.S. Federal Reserve Chairman Ben S. Bernanke, May 2011.
}

Economic growth in high-wage economies such as Europe and the United States stems in good part from investments in knowledge creation-areas where these countries arguably have their greatest comparative advantage. Investments in knowledge creation include expenditures for human capital, in the form of education and training, public and private scientific research, and business expenditures for product research and development, market development, and organizational and management efficiency. Such expenditures - collectively called intangibles - are strategic investments in the long-run growth of individual companies and of the economy as a whole. They are seen by policy makers as essential for sustained economic health as witnessed by the European Lisbon Strategy to revitalize growth, competitiveness, and sustainable development and passage of the America Competes Act in the United States.

In order to manage intangibles as a source of growth at macroeconomic level and driver of value creation for individual firms, it is important to measure them well. U.S. Fed Chairman Ben S. Bernanke expressed this sentiment in his keynote address to an international conference on intangibles held at Georgetown University in Washington, D.C. in May 2011. ${ }^{1}$ But while few would disagree with the long-lasting benefits of intangibles, their costs are expensed in company financial statements and national income and product accounts, implying that they detract from company value and economic growth rather than contributing to it.

Conventional measures of business investment in national accounts consist primarily of tangible assets such as plant and equipment, vehicles, office buildings and other commercial structures. Estimates patterned after work by Corrado, Hulten and Sichel

\footnotetext{
${ }^{1}$ The precise statement is above. See http://www.federalreserve.gov/newsevents/speech/bernanke20110516a.htm
} 
(2005, 2009) on the United States show that in many advanced countries, however, business investment in intangibles approaches the value of investment in tangible assets - and in some cases (such as in the United Kingdom and the United States) investment in intangibles exceeds investment in tangibles. In recent decades, the treatment of intangibles has begun to change with the decision to capitalize software expenditures and treat the result as a contribution to GDP. And many European countries and the U.S. Bureau of Economic Analysis (BEA) will count R\&D as investment in their headline GDP measures in future revisions or in satellite accounts until then.

Much recent work on intangibles focuses on Europe and is comparative in nature. This refers to two projects funded by the European Commission (COINVEST and INNODRIVE) under the $7^{\text {th }}$ Framework Program and to work conducted by The Conference Board and issued by the European Investment Bank (EIB) in December 2009. ${ }^{2}$ These projects generated estimates business intangible investment and capital for much of Europe. In this paper we extend these estimates and review some of the ways that the projects have enhanced understanding the sources of growth in modern advanced economies. A forthcoming companion paper probes more deeply into channels that explain how and why our findings may be important for economic policy.

\section{Goals of paper}

Earlier work documented the differences between the estimates of intangible investment produced by the COINVEST and INNODRIVE projects (Jona-Lasinio 2011). The first goal of this paper is to summarize the state of intangibles measurement with the goal of reconciling the two sets of estimates.

One of the EC-funded projects emphasized consistent, improved estimation of intangible investment across countries while the other encouraged in-depth research and countryspecific approaches. In this paper we embrace both approaches. We propose and implement a general framework for the estimation of business intangible capital, but one in which country-specific values for certain parameters are present. A primary contribution of this paper then is the production of "harmonized" estimates of intangible investment for the EU27 countries and new consistently calculated growth accounts

\footnotetext{
${ }^{2}$ The authors were partners in these projects, and the EIB piece (van Ark, Hao, Corrado, and Hulten 2009) grew in part out of The Conference Board's participation in COINVEST. For the full range of works, see: http://innodrive.org/ http://www.coinvest.org.uk/bin/view/CoInvest http://www.conference-board.org/data/intangibles/
} 
including intangible capital for 14 of them; new estimates for the United States using the same approach are also provided.

We review the strengths and weaknesses of existing approaches to measuring intangible investment and capital and make three contributions to the current state of the art. First we introduce a labor-based production cost method for measuring investment in new financial products. Relative to Hunt (2000), who sought to quantify "R\&D” in financial services on the basis of "research" positions in the industry, as well as work done on France and the UK as part of the COINVEST project, our approach considers quantitative finance occupations. ${ }^{3}$ Second, we consider the important role that ownership has in the context of national accounts and strengthen the case for capitalizing intangibles though examples and a review of the economic elements behind the calculation of net stocks using the perpetual inventory model. Although we illustrate how and why intangibles tend to have short service lives relative to tangibles, our review of current practice leads us lengthen lives used for R\&D. Third, we make a modest attempt at attacking the issue of price deflators for intangibles. Based on a suggestion in the Handbook on Deriving Capital Measures of Intellectual Property Products (OECD 2010), we implement a new method for calculating harmonized software deflators. On balance, the move improves comparability of EU growth accounting results with the US.

The analysis of European economic growth with intangibles based on the work of the projects has already garnered a fair bit of attention (e.g., in the OECD’s Innovation Strategy). Indeed, the projects produced a substantial body of conceptual, technical, and analytic work highly relevant to policy. Examples of the findings include:

- Investment in intangible capital, which includes R\&D and the software component of ICT, is largely investment in innovation.

o GDP (and gross saving and investment rates) are 5 to 10 percent (percentage points) higher when intangibles are classified as investment compared with when they are excluded.

o A substantial part of the market value of companies is explained by intangible capital.

- Intangible capital deepening accounts for about one-quarter of labor productivity growth in the larger countries of the European Union and in the United States.

\footnotetext{
${ }^{3}$ The approach is based unpublished work by Carol Corrado and Janet Hao who developed the grouping from information on the work activities of detailed occupations provided in $\mathrm{O} * \mathrm{Net}$ (a product of the U.S. Department of Labor)..
} 
- The non-rival nature of intangible capital implies a theoretical link to total factor productivity growth via diffusion, and spillovers from intangibles likely exist beyond the well-researched effects from R\&D.

- Also across countries, higher rates of investment in intangibles are associated with higher growth rates of GDP per capita - a finding that might be attributed to greater financing opportunities but also could be related to a higher propensity to invest in knowledge capital in higher-income (and higher-productivity) countries.

A second goal of this and a companion paper is to reinforce and extend these findings using the harmonized estimates and additional years of data.

\section{Capitalizing intangibles reveals investments in innovation}

The link between productivity, intangible assets and innovation has roots in numerous literatures, including the work on returns to investments in R\&D and ICTs and studies of innovation in services industries. ${ }^{4}$ The contribution of Corrado, Hulten, and Sichel (2005, 2009, hereafter CHS) was to use an economic view of investment to formalize the arguments for capitalizing a broad range of intangibles (not just R\&D and software) in company and national accounts. Because such a move spotlights the overall commitment of a company or a nation to innovation, the work gained attention by macroeconomic policy and growth analysts.

The status of tangible assets as capital is indisputable. Such assets are created when today's resources are set aside and used to expand tomorrow's production capacity. The criterion applies equally to firms' expenditures on product, market, and organizational development because firms expend resources on such activities to increase their future production capacity through "organic growth", or innovation. This view of investment is common sense, yet it is firmly grounded in economic theory via the optimal growth literature (e.g., Weitzman 1976; see also Hulten 1979).

\subsection{Model}

CHS advanced a simple three-sector model that specified production functions for consumer goods, conventional investment goods, and intangibles. The model was used to show how an economy's input and output growth changed when business investment in intangibles was capitalized, and its variables were used to identify the prices and

\footnotetext{
${ }^{4}$ Of course, researchers and business strategists came late to the services revolution, and the literature in this field is sparser and less well known than the work on the productivity-enhancing impacts of investments in R\&D and ICTs.
} 
quantities that needed to be measured in order to capitalize intangibles and study their contribution to growth.

Here we follow the same strategy but use the related model in Corrado, Goodridge and Haskel (2011) because it focuses on innovation. The model has two sectors, an upstream or knowledge-producing sector and a downstream or knowledge-using sector. The upstream sector takes freely available concepts or ideas-basic knowledge-and produces "finished" ideas or commercial knowledge (e.g., blueprints), $N_{t}$. Another way of thinking about the two sectors is that one is the "innovation" sector and the other is the "production" or "final output" sector.

Commercial knowledge is an input to downstream production, whose output is the sum of consumption and investment and whose value is given by $P^{Y} Y_{t}=P^{C} C_{t}+P^{I} I_{t}$. The commercial knowledge is non-rival and appropriable, but only for a time. It is in fact sold at a monopoly price to the final output sector during the period of appropriability. In other words, the downstream sector is price-taker for knowledge. This feature of the model - that product market power is temporary and located in the innovation sector-is similar to the models of Romer (1990) and Aghion and Howitt (2007), among others. ${ }^{5}$

The production functions and factor payment equations for the two sectors are written as follows:

$$
\begin{array}{cc}
N_{t}=F^{N}\left(L_{t}^{N}, K_{t}^{N}, R_{t}^{N}, t\right) ; & P_{t}^{N} N_{t}=\mu\left(P_{t}^{L} L_{t}^{N}+P_{t}^{K} K_{t}^{N}\right) \\
Y_{t}=F^{Y}\left(L_{t}^{Y}, K_{t}^{Y}, R_{t}^{Y}, t\right) ; & P_{t}^{Y} Y_{t}=P_{t}^{L} L_{t}^{Y}+P_{t}^{K} K_{t}^{Y}+P_{t}^{R} R_{t}^{Y}
\end{array}
$$

\footnotetext{
${ }^{5}$ The basic structure of the upstream-downstream model also is similar to the underlying model in Romer (1990). Romer has three sectors: (1) an" ideas" sector that uses all knowledge in the economy freely as an input into production of ideas (along with labor), (2) a "design" sector that converts ideas into "blueprints," and (3) the "production" or "final output" sector that uses blueprints as an intermediate good. The blueprints are thus bundles of knowledge that are assumed appropriable (via patents, say) and sold at a monopoly price to the final output sector. Romer also notes (p. S84) that the use of a blueprint in production is rival to produce good 1 , but the knowledge in that design is non-rival and can be studied and potentially used to produce good 2 . The commercial knowledge sector of the upstream-downstream model can be thought of as Romer's “design” sector (which he notes can of course be in-house).

In perhaps a less obvious parallel, Corrado, Goodridge, and Haskel (2011) show their upstreamdownstream model is observationally equivalent to equilibrium models of imperfect competition (e.g., Rotemberg and Woodford 1995).
} 
The production functions have three factors of production, labor $(L)$, capital $(K)$, and knowledge $(R)$, superscripted by $N$ or $Y$ depending on sector of usage. In the factor payment equations, $P^{L}$ and $P^{K}$ are competitive factor prices for services supplied, per unit of labor and capital input, respectively.

The stock of commercial knowledge $\left(R^{Y}\right)$ is the accumulated output of upstream production $(N)$, which grows via the perpetual inventory relation:

$$
R_{t}^{Y}=N_{t}+\left(1-\delta^{R}\right) R_{t-1}^{Y}
$$

where the term $\delta^{R}$ is the rate of decay of appropriable revenues from the existing stock of commercial knowledge. This concept of depreciation was introduced and applied to the conduct of private R\&D by Pakes and Schankerman (1984).

In the upstream factor payments equation, there are no payments to basic knowledge $R^{N}$ because its services are free, from universities say, and determined outside the model. The parameter $\mu \geq 1$ is a measure of the degree of market power, the "innovator" markup over competitive factor costs of inputs used up in the innovation process. This parameter varies across industries as it depends on customers' price elasticity of demand for an industry's products (think new Apple products vs. new varieties of bubblegum).

In the downstream factor payments equation, $P^{R}$ is the price of renting a unit of the finished knowledge stock (e.g., a license fee for a patent or blueprint). The user cost expression gives the relationship between $P^{N}$, the price of a unit of newly produced finished knowledge (an investment or asset price), and its unit rental price:

$$
P_{t}^{R}=P_{t}^{N}\left(r_{t}-\pi_{t}^{R}+\delta^{R}\right)
$$

where $r_{t}$ is the net rate of return common to all capital in year $t$ (taxes are ignored) and $\pi_{t}^{R}$ is the expected capital gain (loss) on intangible capital, i.e., the expected rate of change of $P^{N}$. Equations similar to (3) and (4) but written in terms of tangible capital complete the model.

\subsection{Model Implications}

Conventional economy-wide GDP growth is given by the growth rate of $Y$ when investments in innovation are not capitalized. But when such investments are capitalized, aggregate value added and its real growth reflect the current production of both sectors. 
Denoting the new value added aggregate as $P^{Q} Q$ and it real growth as $d \ln Q$, after capitalization, we have:

$$
\begin{aligned}
& P^{Q} Q=P^{Y} Y+P^{N} N=P^{C} C+\underbrace{P^{I} I+P^{N} N}_{\text {Total Invesment }} \\
& d \ln Q=\frac{P^{Y} Y}{P^{Q} Q} d \ln Y+\frac{P^{N} N}{P^{Q} Q} d \ln N
\end{aligned}
$$

As suggested by the first line of (5), capitalizing intangibles changes an economy's (gross) saving and investment rates. These rates are larger because the resources the economy devotes to innovation have been included. As suggested by the second line of (5), when saving and investment rates are constant and $Y$ and $N$ grow at a common rate as in balanced growth (or perhaps simply because $P^{N}$ is set equal to absent independent information on $P^{N}$ ), capitalizing intangibles does not alter the rate of growth of aggregate real value added.

Balanced growth is, of course, a special case as is the assumption that $P^{N}=P^{Y}$. In reality, a consequence of capitalizing intangibles is the creation of composition effects on real growth (Corrado and Hulten 2010). Intangible investment includes the ways that modern companies create competitive advantage, and as previously noted, available estimates place the growth of intangible investment relative to tangible investment firmly in positive territory for most European countries and the United States for close to 15 years. This owes, in part, to a burst of software and organisational investment associated with the flurry of investment computer hardware and Internet revolution of the late 1990s. The dynamics of the relationship between tangible and intangible investment has changed somewhat in recent years, as we show and discuss later in this paper.

Capitalizing intangibles also changes the picture of the factors that account for economic growth. Growth accounting decomposes the rate of change of real aggregate output into contributions from changes in human, tangible, and intangible inputs on the one hand, and changes in the efficiency with which those inputs are combined on the other. The latter is of course the TFP residual famously described by Abramovitz (1956, p. 11) as "the measure of our ignorance." Capitalizing intangibles arguably diminishes this 
ignorance because the contribution of the production and use of knowledge to economic growth is revealed. ${ }^{6}$

Aggregating value added inputs across the sectors (recall our assumption of competitive markets for labor and tangible capital) ${ }^{7}$ yields an expression for the sources of growth in value added output after capitalization of intangibles as:

$$
d \ln Q=s_{Q}{ }^{L} d \ln L+s_{Q}{ }^{K} d \ln K+s_{Q}^{R} d \ln R+d \ln T F P^{A}
$$

compared with before capitalization:

$$
d \ln Y=s_{Y}{ }^{L} d \ln L+s_{Y}{ }^{K} d \ln K+d \ln T F P^{B}
$$

where $L=L^{Y}+L^{N} ; K=K^{Y}+K^{N}$; and $R=R^{Y}$. The s-terms are factor income shares for the alternative measures of aggregate value added.

The two TFP terms are superscripted by A and B, respectively, to distinguish measures "after" and "before" capitalization of intangibles. When intangible investments are an increasing share of output, measured $d \ln T F P^{A}$ will tend to be smaller than $d \ln T F P^{B}$, but as just noted, this is not an inevitable consequence of adding intangible capital.

\subsection{Model implementation}

Capital measurement is a three-legged stool: Information on asset valuations $P^{N} R$, asset incomes $P^{R} R$, or asset investment flows $P^{N} N$ could be the starting point for empirical analysis. The studies by Hall (2000, 2001a, 2001b) and McGrattan and Prescott (2000, 2005), for example, employ strategies that exploit valuations and incomes. These studies and the work of Lev (2001) and Baumol (2002), among others, establish that the appropriation of knowledge capital is a routine matter in business and that modern business realities support extending the current asset boundary to include intangibles in national accounts.

\footnotetext{
${ }^{6}$ In the special case of an economy in maximal consumption (or "golden rule") balanced growth, TFP growth itself does not change with the introduction of new capital goods (Jorgenson 1966; see Hulten 2009 for further discussion). However, even on a maximal consumption growth path, the relative contributions of productivity and factor inputs are altered when a capital good or intangible investment is added to GDP. For more discussion and an example, see Corrado, Goodridge, and Haskel (2011).

${ }^{7}$ The prices $P^{L}$ and $P^{K}$ in (1) and (2) are written to be identical across the sectors, but in reality there are different types of labor and capital inputs and composition effects may cause sector aggregates to differ even though the underlying input prices by type are competitive and equalized (by type) across sectors.
} 
With this objective in mind and because an expanded asset boundary implies an expanded boundary for current production, we begin with the augmented GDP identity equation (5) and proceed by estimating nominal intangible investment flows consistent with the "new" GDP and "new" investment propensity. This was the approach taken by Nakamura (2001) and then by CHS, who in turn proceeded to build intangible capital estimates by asset type for inclusion in productivity accounts and empirical growth analysis as per equations (6) and (7).

Enhancing the relevance of intangible capital measures for sources-of-growth analysis is a key goal of this paper, as is enhancing the relevance of intangible capital for national accounting practice. In national accounts, a fixed asset must meet several criteria, one of which is that legal and economic ownership must be exercised on it. Accordingly, in implementing the model of section 1, we include discussions of how intangible capital (and its measurement) meets the national accounting criterion of ownership.

\section{Empirical measurement}

When questioned about the relevance of the existing asset boundary for intangibles in national accounts nearly six years ago, U.S. BEA Director Steve Landefeld answered, "No one disagrees with [the capitalization of intangibles such as R\&D] conceptually. The problem is in the empirical measurement." ${ }^{8}$ Since then researchers and practitioners at national statistical offices and international organizations, along with the partners of COINVEST and INNODRIVE, have done much to remedy "the problem in empirical measurement”.

The model and above discussion suggests that to estimate intangible capital and analyze its role in economic growth as per equations (6) and (7), we need:

- A list of intangible assets to be measured.

- Magnitudes for the nominal investment flow $P^{N} N_{t}$ for each asset type.

- A means to separate these flows into price $P^{N}{ }_{t}$ and quantity $N_{t}$ components.

- Service lives of each asset to enable the compilation of net stocks $R_{t}$.

We discuss each of these tasks in turn.

\footnotetext{
${ }^{8}$ Reported on page 66 of “Unmasking the Economy,” Business Week (February 13, 2006, pp 62-70) by Michael Mandel.
} 


\section{$\underline{3.1 \text { Asset types }}$}

The first task is to identify all relevant intangible asset types. CHS (2005) choose assets in terms of three broad categories: computerized information, innovative property and economic competencies. They populated these categories with nine asset types, with the resulting list similar to that used by, e.g., competition agencies when valuing assets for a company under scrutiny, or tax guides for reporting the value of financial assets following a corporate merger or acquisition. Although such practices developed independently, like the intangible capital literature, they tend to embrace modern business realities and value assets whose ownership is not typically protected by legal covenants. ${ }^{9}$

To determine whether an outlay is investment, it is necessary to distinguish current production costs from expenditures that expand future productive capacity. This distinction is made on the basis of the expected service life of the outlay, which national accountants usually set as longer than one year. With regard to intangibles, the System of National Accounts (SNA) 1993 recommends the costs of producing artistic originals and computer software, and the expense of mineral exploration be treated as fixed investments. To that the SNA 2008 adds the conduct of R\&D, a development that emerged following the resurgence of interest in intangibles in the early 2000s. ${ }^{10}$

While all this sounds straightforward, sometimes the status of R\&D or other new CHS assets has been questioned. ${ }^{11}$ The typical argument usually goes something like this: "You can't include [fill in the blank, e.g., design costs] in investment. That is doublecounting because it is already included in the value of [fill in the blank, e.g., equipment or structures].” The flaw in this reasoning is exposed in the upstream/downstream nature of innovation as set out in the model of section 1: one way or another the costs of innovation must be "covered" by revenues from final sales. Moreover, according to the double-

\footnotetext{
${ }^{9}$ For example, the UK Competition Commission inquiry on the provision of Home Credit valued: (a) corporate reputation/brand (b) the trained workforce (c) the customer base (d) and IT systems and development. (For details on methods, see the commission's report Home Credit Inquiry, 2006, Appendix 3-6 and 3-8). And the US tax code specifies 12 intangible assets to be valued and listed as financial assets following a merger or acquisitions, including the value of the business information base, the workforce in place, know-how (listed along with patents and designs), and customer and supplier bases. (See US IRS Publication 535, Business Expenses, pp. 28-31).

${ }^{10}$ The official implementation of SNA recommendations can take as long as a decade, however, and although there generally is harmonization of practices across Europe, the official statistics of a country (or Europe) may at times be inconsistent with the statistics of other (or non-European) countries. The publication of satellite accounts greatly mitigates the difficulties analysts face in using official statistics during a period of change.

${ }^{11}$ Sometimes even what is meant by investment is questioned, to which the answer of course is "any use of resources that reduces current consumption in order to increase it in the future” (CHS 2005, p. 19).
} 
counting argument machine tools_-machines that make machines - are not investment. The criterion for capitalization is the service life of the outlay, not its stage in the process of production. $^{12}$ If machines only lasted for a year and therefore were "used up" in current production, one would subtract their acquisition cost from the value of production to measure value added. But most machines and designs are not "used up” in current production, and only by capitalizing their costs will value added be correctly measured.

The CHS list attempted to include all other costs of developing and launching new products and services, including market research (usually excluded from $R \& D^{13}$ ), and all costs of improving production processes (including services delivery systems) beyond outlays on conventionally defined ICT and R\&D. With regard to ICT as conventionally defined, an issue at the time of the CHS work-indeed, an issue now emerging in the popular press-is how to account for the value of databases. SNA 1993 recommended capitalizing investments in databases (along with software), but as a practical matter the issue remains unresolved. Generally speaking, the position of national accountants tends to be that investments in databases are captured in current software measures. ${ }^{14}$

With regard to R\&D, the approach of CHS was to substantially expand the traditional notion of product and process $R \& D$, an approach generally accepted by both European projects. The basic idea was to include (1) the nontechnological costs of design (industrial and nonindustrial) and services innovation (including investments by financial services firms not captured by R\&D surveys), (2) the costs of marketing and launching new products, including ongoing investments to maintain the value of a brand, and (3) organization and human capital management innovations.

\footnotetext{
${ }^{12}$ On the other hand, perhaps the underlying concern of the "double-counting" view is that an intangible asset may be bundled with another asset, as in computers with software already installed, but that is not what is usually said. As an aside, we note that when comparisons of intangible and tangible investment rates are made, the software (or intangible) that is bundled with hardware (or tangible) is counted with the hardware (or tangible).

${ }^{13}$ Practice in the EU and US diverges a bit in this regard. In the United States, all forms of social, demographic, and actuarial research, as well as artificial intelligence, management science, and geophysical research were explicitly excluded from the expenditures collected $R \& D$ surveys until 2008. The basis shifted in that year to the same basis used for R\&D in company reports, but an instruction to exclude market research remains.

${ }^{14}$ The Handbook on Deriving Capital Measures of Intellectual Property Products (OECD 2010, p. 120ff) reports that a survey of OECD member countries found that, of the 13 countries who responded to the survey, 8 said that they capitalized databases in principle, but that the values were not separately identifiable (OECD 2004).
} 
Table 1 shows the CHS list, which was not changed or refined in material ways by the European projects. Data sources and estimating methods were, of course, adjusted according to availability for European countries. And in some cases experimental estimating methods were pursued, one of which we modify and adopt in this paper.

\begin{tabular}{|lc|}
\hline \multicolumn{2}{|c|}{ Table 1. Intangible Capital Asset Types } \\
\hline Asset type & $\begin{array}{c}\text { Included in } \\
\text { National } \\
\text { Accounts? }\end{array}$ \\
\hline Computerized information & Yes \\
\hline 1. Software & ? $^{1}$ \\
\hline 2. Databases & Yes \\
\hline Innovative property & Satellite for some ${ }^{2}$ \\
\hline 3. Mineral exploration & EU-yes, US-no ${ }^{3}$ \\
\hline 4. R\&D (scientific) & No \\
\hline 5. Entertainment and artistic originals & \\
\hline 6. New product/systems in financial services & No \\
\hline 7. Design and other new product/systems & No \\
\hline Economic competencies & No \\
\hline 8. Brand equity & No \\
\hline a. Advertising & \\
\hline b. Market research & \\
\hline 9. Firm-specific resources & \\
\hline a. Employer-provided training & \\
\hline b. Organizational structure & \\
\hline 1. SNA 1993 recmmended captalzngcompterzed atases. & \\
\hline
\end{tabular}

1. SNA 1993 recommended capitalizing computerized databases.

2. R\&D satellite accounts are available, or under preparation many countries. Results for Finland, Netherlands, United Kingdom, and the United States are publically available.

3. The US BEA plans to include entertainment and artistic originals and R\&D as investment in headline GDP in a revision in 2013.

Before leaving this discussion of the utility of table 1, consider the emerging literature on the important role played by startups and young, small firms in successful innovation ecosystems. One might therefore ask, how do angel and venture investments fit into the scheme shown in table 1? Venture investment was not included in the CHS estimates, and therefore to answer this question we examine the relationship between venture investment and the available data on R\&D and marketing. If angel and "seed" venture funds are used for the conduct of R\&D in very small firms, such funds are unlikely to 
overlap with official R\&D statistics already included in intangible investment. ${ }^{15}$ Nor will they overlap if the funds do not seed a science or engineering-based endeavor, however large or small the firm.

Consider now the "startup" or "first stage" venture funding. These funds are for expenses associated with marketing and product development. ${ }^{16}$ This type of investment is exactly what intangibles investment aims to capture. But if these funds are expended within the firm, they will not be captured in CHS-based measures of intangible investment. Why? Because owing to measurement difficulties, own-account design (line 7) and market research (line 8b), the two most closely related intangible components, are not typically included in estimates of intangible investment.

Given these arguments, we ask, What is the relationship between intangible investment measured according to the scheme in table 1 and the available data on early-stage venture funding? The results are shown in figure 1 below. As may be seen, intangible investment as a ratio to GDP and early-stage venture investment as a ratio to GDP is rather strongly correlated across European countries and the US (based on 2000 to 2007 averages). The result bears closer scrutiny so that the underlying causal and timing mechanisms can be better understood. But equally interesting is simply the fact that the two innovation indicators line up with one another (when averaged over time), lending credence to the argument made in this paper and elsewhere that intangible investment is an indicator of innovative activity.

\footnotetext{
${ }^{15}$ R\&D surveys in Luxembourg, Netherlands, Sweden, and the United States all use a lower bound cut-off to draw samples for small firms (5 to 49 in the United States, and 10-49 in the other three).

${ }^{16}$ According to a popular corporate finance textbook (Ross and Westerfield, as reported in Wikipedia, "Venture Capital", accessed 3/20/12), there are six stages of venture round financing that generally correspond to a stage of a company's development.

- Seed money: Low level financing needed to prove a new idea, often provided by angel investors. Crowd funding is emerging as an option for seed funding.

- Start-up: Early stage firms that need funding for expenses associated with marketing and product development

- Growth (Series A round): Early sales and manufacturing funds

- Second-Round: Working capital for early stage companies that are selling product, but not yet turning a profit

- Expansion : Also called Mezzanine financing, this is expansion money for a newly profitable company

- Exit of venture capitalist : Also called bridge financing, 4th round is intended to finance the "going public” process
} 
Figure 1. Intangible Investment and

Early-Stage Venture Capital, 2000-07

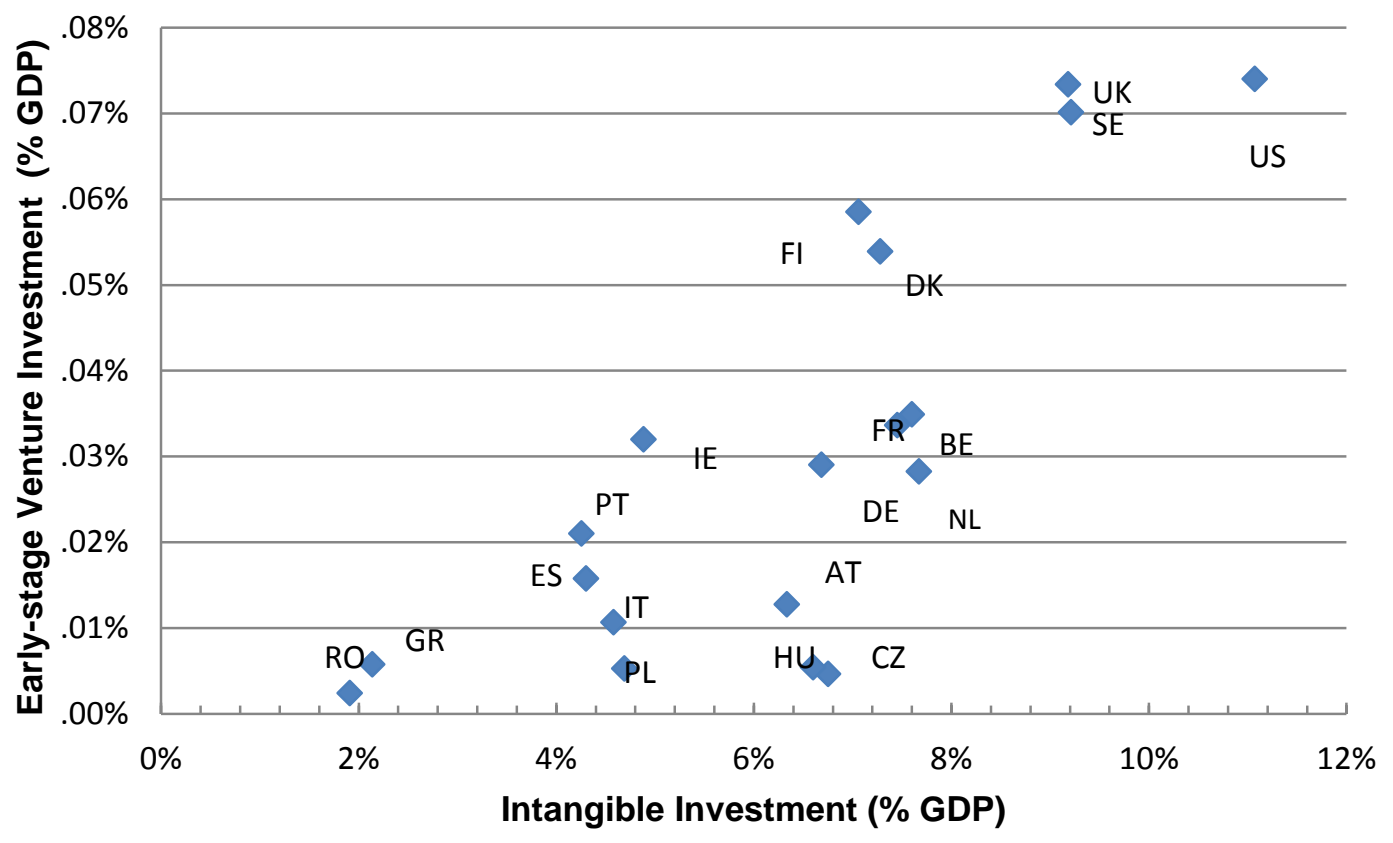

\subsection{Nominal investment flows}

Associated with each asset listed in table 1 is a data source for intangible spending. A second task therefore is to decide how much of an identifiable data series on intangible spending is investment, i.e., what portion of an indicator series fits the definition of investment as "any use of resources that reduces current consumption in order to increase it in the future" (CHS 2005, p. 19). In other words, we may have determined that spending by TV companies on original theatric movies constitutes a long-lived investment, but as a matter of data, we may only have spending on, say, all TV programs. The fraction of an identifiable data series on intangible spending that is investment is its capitalization factor. Direct survey data are, of course, preferred to indirect estimates using indicators and capitalization factors. ${ }^{17}$

\footnotetext{
${ }^{17}$ The emerging survey work in the United Kingdom (Awano, Franklin, Haskel, and Kastrinaki 2010) offers a promising approach for improving the accuracy of measured intangible investment. We note of course that measuring intangible investment is a different approach than used in the European innovation surveys. Questions in these surveys ask about spending on, say, training that is devoted to innovation. This seems attractive at first blush, but there are a number of reasons to be cautious in using these data. First, in practice, these spending questions have poor response rates. Second, the intangible investment approach relies on firms being able to report spending that lasts more than one year. The innovation survey approach
} 
Capitalization factors are usually set equal to one because knowledge of how much of a measured expenditure is investment is lacking. In certain cases such as advertising spending, however, studies of longevity are available and suggest factors should be less than one because only the national, or major-campaign type of spending has been found to generate long-lasting benefits to a company's brand/sales or reputation. In principle, of course, a capitalization factor can also exceed one. R\&D surveys usually restrict the $\mathrm{R} \& \mathrm{D}$ boundary to activity that is strictly experimental and/or grounded in science and technology. As a practical matter in certain industries, other investments in innovation, such as testing and production trials, could be represented as a multiple of surveyed R\&D costs.

Third, one needs to account for all sources of supply. Although many intangible assets are self-produced, new investment stems both from the work a company conducts inhouse plus the services or assets it purchases from other companies. Markets for intellectual property and organizational innovation services are growing and/or are firmly in place in many advanced countries, and aggregate services from intangible assets increasingly are a mix. To obtain unbiased estimates of investment, therefore, it is necessary to identify and account for both sources of supply.

Unbiased estimation of intangibles also requires consistent valuation of self-production and marketed services. This is done by including a markup on own-production costs, as in the upstream factor payments equation of the model set out above. ${ }^{18}$ With an increasingly large share of intangible assets and services (technology licenses, patents and copyrights and management and consultancy services) traded through markets, the imputation of "shadow" values for within-company production and use will in all likelihood become a more prominent aspect of the analysis and measurement of business investment in intangibles. ${ }^{19}$

requires firms to know what innovation is, which in turn requires defining innovation and assuming firms interpret the question and instructions in a consistent manner.

${ }^{18}$ In the U.S. R\&D satellite account, the costs of R\&D exchanged between R\&D establishments classified in a different industry than the parent/owner firm were marked up for this reason (Moylan and Robbins 2007, p.52).

${ }^{19}$ As an example, Hulten and Hao (2008) studied six multinational pharmaceutical firms and estimated that the "shadow" value of own-produced pharmaceutical R\&D was 50 percent greater than its cost (i.e., the innovator markup on R\&D was 1.5) in 2006. 
Fourth, one needs to determine the level of disaggregation used for estimation. In the original CHS work, the aggregate business sector was used, and most studies that followed have done the same (including the COINVEST and INNODRIVE projects). An exception was the pioneering work on Japan (Fukao et al. 2009) that disaggregated according to manufacturing and nonmanufacturing. Since the emergence of the Japanese work, researchers in other countries have also experimented with disaggregate sector and industry-level estimates of intangibles. ${ }^{20} \mathrm{~A}$ recurring question in the analysis of intangibles and economic growth has been whether the increased importance of intangibles in advanced economies owes to the relative growth of services production. Disaggregated estimates may be needed to answer these and other structural questions satisfactorily.

Finally, one needs time series of sufficient length for the analysis of economic growth. The availability of a periodic survey or research-based benchmark for each intangible investment type is available (at best) only for certain years; and often they are very recent years. To develop historical time series, it may be necessary to link benchmark data to annual estimates of production costs for earlier years developed, say, from existing surveys of wages and employment by occupation and/or industry. The U.S. estimates of firm-specific employee training are estimated from 1947 on using this technique.

Taking all these considerations into account yields a general expression for estimating nominal intangible investment for a country or a region as follows:

$$
\begin{aligned}
P^{N} N_{t} & =\sum_{j=1}^{J} \mu_{j}\left(P^{L} L_{j, t}+P^{K} K_{j, t}+P^{M} M_{j, t}\right) \\
& =\sum_{j=1}^{J} \mu_{j}^{\text {shadow }}\left(P^{L} L_{j, t}+P^{K} K_{j, t}+P^{M} M_{j, t}\right)^{\text {own-account }}+P_{j}^{N} N_{j, t}^{\text {purchased }} \\
& \cong \sum_{j=1}^{J} \sum_{s=1}^{S}\left(\mu_{s, j}^{\text {shadow }}\left(P^{L} L_{s, j, t}+P^{K} K_{s, j, t}+P^{M} M_{j, t}\right)^{\text {own-account }}+P_{j}^{N} N_{s, j, t}^{\text {purchased }}\right) \\
& =\sum_{j=1}^{J} \sum_{s=1}^{S}\left(\mu_{s, j}^{\text {shadow }} \lambda_{s, j} \text { OwnCost } \text { Indicator }_{s, j}+\gamma_{s, j} \text { Purchased }_{s, j, t}^{\text {Indicator }}\right)
\end{aligned}
$$

In this equation, $P^{N} N$ is first expressed as an aggregate of $J$ assets using terms set out for the model of section 2.1 (but here we of course include the intermediate inputs used in the production of the intangible). Note as in equation (8), a closed economy is assumed.

\footnotetext{
${ }^{20}$ e.g., Barnes (2010) and Dal Borgo, Goodridge, Haskel and Pesole (2011).
} 
The first line of equation (8) holds whether an economy's intangibles are self-produced or marketed purchases. What changes when investment moves from the former to the latter is the origin of the markup, namely, whether it is an imputed "shadow" value or a factor embedded in transactions data (i.e., embedded in $P^{N}$ ). To underscore this equivalence, the second line of equation (8) expresses intangible investment in terms of both sources of supply. The superscript "own-account" denotes intangibles produced and consumed within the same firm. ${ }^{21}$

The third line of equation (8) is a more general expression where aggregation now is over a subset of private domestic sectors (S). This line is conceptually equivalent to the first two lines in the absence of public investments and international trade in intangibles and underscores that, to date, most work on measuring intangibles has concentrated on private, not public, investments. ${ }^{22}$ As to the internationalization of intangibles, very little is known with the exception of $\mathrm{R} \& \mathrm{D}$. As a practical matter, net international trade in R\&D remains relatively small for many major EU countries and the United States but is consequential for others, such as Finland. In general, trade in services, especially business and professional services, is expanding rapidly (e.g., Jensen 2011), and the internationalization of intangibles is an important topic for future work. Here we simply note that, in reality, when intangibles are capitalized, the adjustments to production and gross domestic capital formation need not be identical as implied by equation (5). ${ }^{23}$

The variables OwnCost Indicator and Purchased Indicator $_{s, j, t}$ in the fourth line of equation (8) are time series indicators of the actual in-house intangible production or purchased intangible assets in each sector. The parameters $\lambda_{s, j}$ and $\gamma_{s, j}$ are sector- and asset-specific capitalization factors that adjust the own cost and purchased indicators to benchmarks for

\footnotetext{
${ }^{21}$ Note that the firm-based own-account and purchased concepts in equation (8) and do not necessarily correspond to the same terms when used in establishment-based national accounting. If a manufacturing firm has a $R \& D$ lab at a separate location, the $R \& D$ survey will allocate the $R \& D$ expenditures of the lab to manufacturing, while the national accounts will allocate it to the R\&D services industry.

${ }^{22}$ An example of an exception is the van Ark and Jaeger (2010) study of public intangibles in the Netherlands.

${ }^{23}$ The collection of direct information on intangibles trade would be very difficult for individual countries. One way of dealing with the trade dimension of intangibles could be to exploit the income flows and available data on asset purchases via a World Input-Output framework [reference to WIOD]. The availability of information about I-O flows of intangibles would allow individual countries to adopt a commodity flow method to measure intangible investments that take into account the international trade dimension. This is an indirect estimation technique commonly used by national accountants to compute gross fixed capital formation, including widely adopted methods used to estimate software investment
} (SNA 1993). 
each asset and sector. As previously mentioned sector cost indicators could be derived from employment surveys (or firm-level micro data as in Piekkola et al. 2011), and sector purchased indicators could be obtained from input-output relationships, from which historical time series can be derived.

Lest this analysis be thought too abstruse, consider the example of capitalizing software. Software is of course an intangible asset capitalized in current national accounts, to be followed by R\&D. The estimates for software investment in the United Kingdom, for example, went through a series of methods changes that can be described in terms of equation (8). In the early experiments with capitalizing software no UK own-account data existed. The first term in the last row of (8) was thus unknown, and UK software spending was determined by a multiple $\gamma$ of purchased software. Initially $\gamma$ was set at 1 , yielding the result that UK software investment was 39 percent of hardware investment, while the same ratio was 140 percent in the United States (Oulton 2002).

Oulton's finding stemmed at least in part from the fact that the U.S. BEA had included an own-account component in its published software investment estimates as in equation (8). The UK software $\gamma$ was then revised to 3 . In a subsequent work for inclusion in the UK headline national accounts, own-account software investment was measured using information on employment and wages in software engineering occupations. In terms of equation (8), then, the parameter $\mu$ was set to 1 and $\gamma$ was set to account for intermediate inputs and to reflect survey information on the fraction of time that workers spend on developing new software vs. user service and routine maintenance (Chamberlin, Chesson, Claytona and Farooqui, 2006). Meanwhile, in its work on a R\&D satellite account, the U.S. BEA found it had counted some software R\&D as own-account software investment (Moylan and Robbins 2007), underscoring the difficulty of indirectly measuring production and use within the same firm.

\subsection{The price element}

Intangible investment in real terms — obtaining each $N_{j}$-is a particular challenge because units of knowledge cannot be readily defined. Although price deflators for certain intangibles (software, mineral exploration, and artistic originals) are found in the national accounts of many countries, generally speaking, output price measures for intangibles have escaped the statistical net.

An exception is the emerging work on price measures for R\&D. The U.S. BEA offered an $R \& D$-specific output price in its preliminary R\&D satellite account (Moylan and 
Robbins 2007; Copeland, Medeiros, and Robbins 2007). A contrasting approach is in a recent paper by Corrado, Goodridge and Haskel (2011), which casts the calculation of a price deflator for R\&D in terms of estimating its contribution to productivity. Applying their method to the United Kingdom yielded a price deflator for R\&D that fell at an average rate of 7-1/2 percent per year from 1995 to 2005-and thus implied that real UK R\&D rose 12 percent annually over the same period. This stands in sharp contrast to the science policy practice of using the GDP deflator to calculate real R\&D (the UK GDP deflator rose 3-3/4 percent per year in the comparable period), and the results of applying the BEA method to the UK data (the UK BEA-style deflator rises 2.1 percent per year).

Other than software and mineral exploration for which deflators are included in the U.S. national accounts, CHS used the overall business output price as the price index for intangible investment. They noted, however, its "place-holder" nature until a more surfaced. As shall be seen, in this paper we maintain this assumption using the EUKLEMS market sector GVA deflator. Until internationally comparable deflators based on the Corrado, Goodridge, and Haskel (2011) — or some other-method are developed, this is our only reasonable choice. ${ }^{24}$ Note that the EUKLEMS market sector GVA deflator is numerically close to the BEA-style output-based R\&D deflator for two countries for which we have these calculations (the UK and the US).

With regard to price measures for intangible capital and the study of factors affecting economic growth in the EU vs. the US, one area that would benefit from additional attention is the harmonization of software prices. The EUKLEMS project harmonized hardware prices (to quality-adjusted US price indexes) but did not harmonize software prices. The OECD implements a simple harmonization procedure for all ICT prices (again to US price indexes) in their calculations of productivity, but their underlying price indexes are not available to the public. The Handbook on Deriving Capital Measures for IP Products (OECD 2010) recommends using a productivity-adjusted cost measure for own-account software and a quality-adjusted measure for pre-packaged and custom software.

\footnotetext{
${ }^{24}$ Because we cannot rule out what could be substantial cross-country differences in R\&D productivity, we believe it is inappropriate to use changes in the UK productivity-based R\&D deflator for other countries. Of course it may also be necessary to consider PPP differences as in Dougherty et al. (2007). Note also that use of an input-cost deflator assumes (1) zero productivity change in the conduct of R\&D, which seems highly unreasonable in light of the IT/Internet revolution, and (2) zero impact of the conduct of R\&D on overall measured productivity growth, which contradicts the extensive literature on R\&D spillovers.
} 
Statistical practice across countries varies. The US has a quality-adjusted pre-packaged software price index, but has been as yet unable to derive independent satisfactory custom and own-account indexes. Thus it assumes that (a) changes in custom and ownaccount indexes are the same and that (b) these changes are a weighted average (0.75 and 0.25 ) of an input cost index and a quality-adjusted pre-packaged index. This composite index is then combined with the quality-adjusted pre-packaged with weights determined by the spending shares of the pre-packaged vs. other components. In this way the ownaccount and custom components of the software price index include a modest degree of productivity improvement, with time variation in the degree determined by the course of the pre-packaged index. The Handbook recommends following a similar approach, using a country-specific input cost index, the US prepackaged software price index, and adjustments for the relative inflation differential between a country and the US.

Given the absence of easy-to-obtain documentation on national statistical offices approaches, we compared the EUKLEMS/national accounts series with the Handbook's recommended approach for $11 \mathrm{EU}$ countries plus Japan. To derive the recommended approach for a country, we constructed each country's own-account measure as a shareweighted average of labor and intermediate input cost changes for industry SIC72 using EUKLEMS data. We then adjusted the US quality-adjusted pre-packaged deflator for the difference between country-specific and US inflation using relative GDP deflators. Finally, we weighted these two measures together using weights based on each country's share of own-account software as set out in OECD (2004). Results for selected countries are shown below (Figure 2). For all countries, this new index was negative on average between 1995-2007 (-0.96 percent per year), reflecting the falling US quality-adjusted pre-packaged deflator (-4.53 percent per year). The existing software deflators in EUKLEMS for Denmark, Slovenia, and the Czech Republic were quite similar to our constructed deflator, but other countries showed higher rates of change. On average, the difference between changes in the EUKLEMS deflator and in our experimental deflator was 2 percentage points per year. 
Figure 2. Experimental harmonized software deflators (annual log differences)

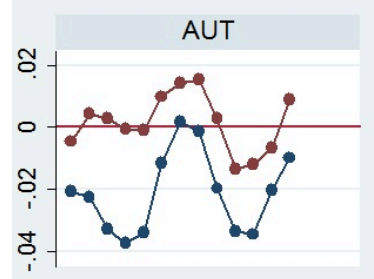

FIN
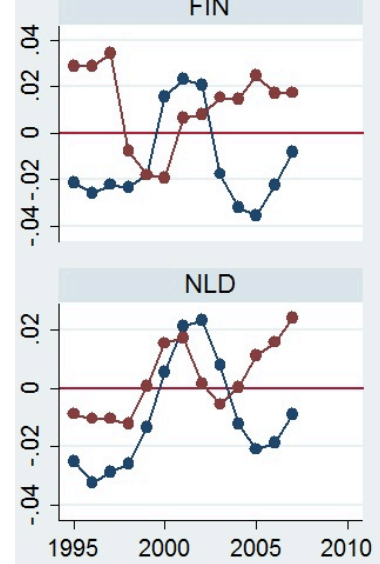

CZE

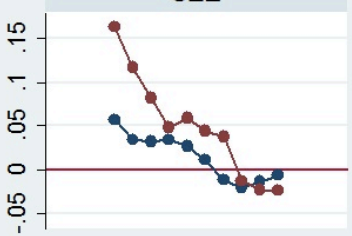

GER

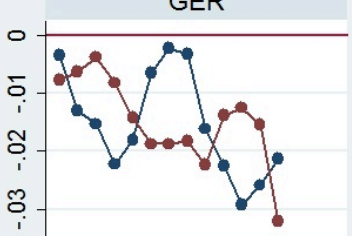

SVN

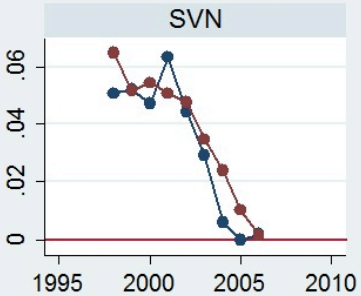

DNK

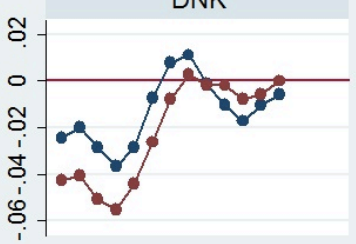

ITA

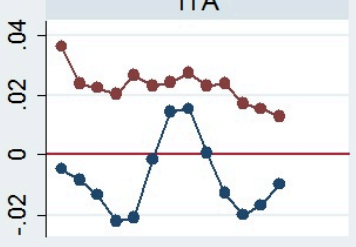

SWE

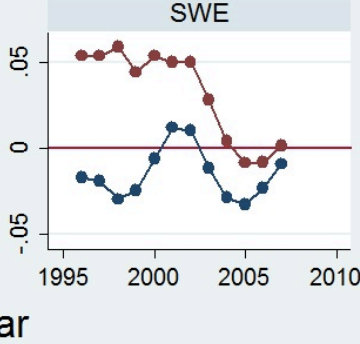

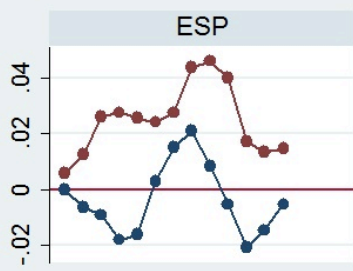

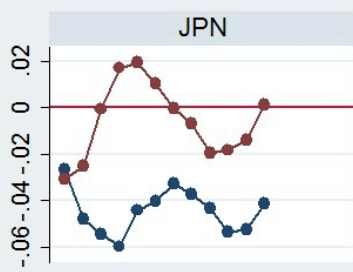

UK

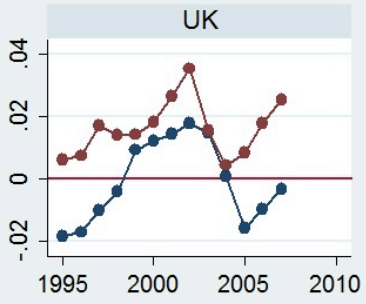

year

\section{$\underline{3.4 \text { Net stocks }}$}

Given the unexpected nature of returns to certain investments in intangibles, it is natural to question the plausibility of equation (3), the perpetual inventory model (PIM), to calculate net stock estimates for intangible capital $(R)$. The task is complicated by several practical theoretical factors, the most important of which is that intangibles are partially non-rival and returns to investments in intangibles are not fully appropriable. Patent protection and business secrecy give the innovator a degree of protection, but the value of the investment to the innovator is limited to the returns on the investment that can be captured, which in turn provides the conceptual basis for measuring depreciation and calculating net stocks.

A sound conceptual basis is a good starting point, but technical and data issues confront the estimation of net stocks of intangibles using PIM nonetheless. Of these, however, the most important is to recognize that a model of economic depreciation must capture two distinct processes, discards and economic decay. One often hears the question, "How can you treat [fill in the blank, say, firm-provided employee training] as an asset of the firm? The firm doesn't own [it.] And [it] can walk out the door.” This concern is akin to the 
"lemons" problem in asset valuation in that some assets tend to fail (or need lots of repairs) at an unusual rate early in their lifetime. The probability that a given asset type will survive in productive use from one period to the next is thus summarized by a stochastic discard, or survival, function.

The productivity of an asset as it ages, conditional on its survival from one period to the next, is described by a decay function. A decay function can be highly concave (i.e., possess an age-price profile bowed out toward the origin) in the case of, say, certain training investments shown to have long-lasting effects for employees who remain with the investing employer. But when a decay function implying long-lasting productivity conditional on survival is interacted with a discard function with a high early failure rate and age cohorts are aggregated, the end result is a convex geometric-like profile that can be summarized using a relatively fast rate of geometric depreciation $\delta$ in the PIM. A series of papers by Hulten and Wyckoff (e.g., Hulten and Wyckoff 1981) revealed this property of economic depreciation. For a technical exposition, see Schreyer (2001). ${ }^{25}$

In a growth accounts framework with geometric depreciation, an estimate of the service life of an asset $\bar{T}$ is usually where one must begin, and then the depreciation rate $\delta$ needed in equation (3) must be derived. Of course, the geometric form of equation (3) implies an age-price profile that is convex toward the origin. To calculate a geometric depreciation rate using an estimate of the mean service life, the formula

$$
\delta=d / \bar{T}
$$

is used. The parameter $d$ is the "declining balance rate," which, intuitively, reflects the degree of convexity of the asset age-price profile. For a given service life, higher values for this parameter result in faster rates of economic depreciation.

\footnotetext{
${ }^{25}$ Oulton and Srinivasn (2003) for example define the real net capital stock of asset $i$ at time $t, K_{i, t}$, as

$$
K_{i, t}=\sum_{\tau=0}^{T} \frac{f_{\tau}}{f_{\tau=0}} F_{i, \tau} \frac{I N_{i, t-\tau}}{p_{i, t-\tau, \text { age }=0}^{A}},
$$
}

where $I N_{i, t}$ is nominal investment in asset $i$ at time $t$. Nominal investment is converted to constant quality real investment by dividing by a quality-adjusted investment price index $p^{A}$ for the new asset at time $t$. $F$ describes "discard" or "survival" as the share of assets from time t still in service in each period (i.e., if it equals 1 or 0 , all or none of the assets are still in existence). $f_{\tau} / f_{\tau=0}$ is the relative marginal product of the investment of age $\tau$ to the marginal product of a new machine, and so captures "economic decay" as a physical quantity concept. Thus a design for example, might exhibit no "economic decay" (that is never "wear out" in a quantity sense), but might be "discarded" as, for example, fashions change. The depreciation rate $\delta$ in the PIM captures the net effect of both these terms. 
Although relatively little is known about depreciation rates for intangible assets, the foregoing discussion implies that their depreciation rates are relatively fast, mainly because of a high rate of "discards" even with little decay (that is productivity of the assets conditional on their continued ownership by, or survival in, the investing firm is long-lasting). On the basis of this thinking CHS set rather high values for $\delta$, especially for the asset types in economic competencies. For example, despite the well-documented fact that advertising campaigns may have long-lasting impacts on a firm's sales and profits, the depreciation rate for brand equity was set to be very fast to account for the fact that some investments in brand result in a competitor's loss of market share and therefore fail to survive as an asset of the industry or sector. For training and organizational capital, the depreciation rate was set lower than investments in brand to reflect the fact that the average tenure of employees in the United States is between 4 and 5 years. Indeed, average employee tenure could be used to set the service life of employer-provided training, and the depreciation rate for employer-provided training could vary across countries, and, in principle, across time.

Since the CHS study, evidence on service lives of intangible assets has accumulated from two main sources. First, in light of the forthcoming capitalization of R\&D in national accounts, experts have weighed in on the subject of depreciation rates for assets recognized in SNA 2008. The U.S. BEA, for example, places its central estimate of the depreciation rate for R\&D at .15, lower (longer) than in CHS (Mead 2007). Also industry specific deprecation rates were used (lower in chemicals, higher in ICT producing industries). In her work in artistic originals for their forthcoming capitalization in the U.S national accounts, Soloveichik (2011) produced depreciation estimates for four categories of total artistic originals that also implied rather long service lives. Her estimates cannot be used in our system because the rates were jointly estimated with advertising and are not applicable to artistic originals alone.

The OECD Handbook on Intellectual Property reviewed national accounting practices on certain intangible assets (software, entertainment and artistic originals, mineral exploration) and states that artistic originals have a 5-10 year lifetime with at least a double-declining balance. But note that if these assets are given more curvature and a longer mean service life than implicit in CHS, the net result as per equation (9) is a geometric rate of depreciation little different from that used by CHS. 
Direct estimates of life lengths from surveys are a second source of new evidence. Surveys conducted by the Israeli Statistical Bureau (Peleg 2008a, 2008b) ${ }^{26}$ and by Awano et al. (2010) with the UK Office of National Statistics. These surveys ask about the "life length" of investments in R\&D (by detailed industry in Israel) and intangible assets (R\&D plus 5 other asset types in the UK). The bottom line is that the Israeli survey supports lengthening the service life for $R \& D$, while the UK survey confirms that the very fast depreciation rates CHS assumed for economic competencies are about right. As a result, in terms of depreciation rates, the main change we make to the original CHS rates is to use a depreciation rate of .15 for $R \& D$. This results in estimates of $R \& D$ stocks that are essentially 5 percent higher than previously calculated.

\begin{tabular}{|c|c|}
\hline Asset type & Depreciation Rate \\
\hline \multicolumn{2}{|l|}{ Computerized information } \\
\hline 1. Software & .315 \\
\hline 2. Databases & .315 \\
\hline \multicolumn{2}{|l|}{ Innovative property } \\
\hline 3. Mineral exploration & .075 \\
\hline 4. R\&D (scientific) & .150 \\
\hline 5. Entertainment and artistic originals & .200 \\
\hline 6. New product/systems in financial services & .200 \\
\hline 7. Design and other new product/systems & .200 \\
\hline \multicolumn{2}{|l|}{ Economic competencies } \\
\hline \multicolumn{2}{|l|}{ 8. Brand equity } \\
\hline a. Advertising & .550 \\
\hline b. Market research & .550 \\
\hline \multicolumn{2}{|l|}{ 9. Firm-specific resources } \\
\hline a. Employer-provided training & .400 \\
\hline b. Organizational structure & .400 \\
\hline
\end{tabular}

The assumptions for individual assets are shown in table 2. Very briefly, the rate for software is from EUKLEMS and is a tad slower than the rate used in CHS. The rate for

\footnotetext{
${ }^{26}$ Peleg S (2008a) 'Service lives of R\&D', Central Bureau of Statistics, Israel. Peleg S (2008b) 'Examples of surveys on service lives of R\&D', OECD Task Force on R\&D and Other Intellectual Property Products.
} 
mineral exploration is the US BEA rate. ${ }^{27}$ The others are as discussed above or the same as CHS.

\subsection{Other Ownership Issues}

Pinning down depreciation rates to satisfy ownership criteria is a key aspect of the measurement of intangible capital. We now touch on two other important issues.

\subsubsection{R\&D - Performer or funder?}

When analyzing the conduct of $\mathrm{R} \& \mathrm{D}$ in private business, by industry or in the aggregate, the productivity literature and science policy analysis has tended to focus on the performer series. The intangible capital literature proceeded in this fashion. National accountants are not necessarily aligned. In the BEA R\&D satellite account, for example, a strong argument for using the funder series as the private business investment series is made. The notion is that the funder series aligns with the ownership basis of the accounts, and that R\&D assets created in the business sector using public funds are assets of the public sector, not the business sector.

BEA seems to be making a technically correct point. But R\&D performed in business and funded by government also has the character of a subsidy, and for productivity analysis one might prefer to use the performer series and treat the government payments as an addition to capital compensation. The R\&D assets so generated would be considered tacit knowledge rather than a legally protected asset (or IPR) created by private R\&D investment. Indeed, it is commonly understood that not all investments in $R \& D$ result in IPRs, and the treatment of publicly funded $R \& D$ as a subsidy is consistent with this reality.

Alternatively one could introduce different assumptions about ownership and appropriation though alternative capitalization factors and depreciation rates of government- or foreign-funded R\&D performed by a domestic business sector. GalindoRueda (2007) does this in his work to construct a R\&D satellite account for the UK. He assumes that 50 percent of $R \& D$ funded by government and performed by business sector

\footnotetext{
${ }^{27}$ The lifetime of the knowledge created by mineral exploration is the service life of the discovery (a well or a mine). In the Australian national accounts, a service life of 34 years is used whereas the United States uses 12 for oil and gas exploration and 20 for mining. Most U.S. exploration is for oil and gas, and a 12year life is used for the calculations reported in this paper. Note that investment is mineral exploration is negligible for most EU countries.
} 
accrues to business, and that 10 percent of $R \& D$ funded by the rest of the world performed by UK business sector accrues to UK business.

\subsubsection{Intangibles and human capital}

One often hears the comment, "Surely investment in [intangible capital asset X] is ultimately investment in human capital. Thus you are double counting with human capital.” Addressing this comment in full would require a complex and wide-reaching discussion but the central issue relevant to this paper is fairly simple, namely, the subject of ownership. Consider the most obvious example, training. If it forms general human capital, then the returns accrue to workers, i.e., the returns are priced into wages and reflected in the marginal product weighting of labor input that appears as the labor composition term in empirical growth accounting analysis.

If training creates firm-specific human capital, however, the returns are not fully reflected in wages. Rather, the firm captures rents, and these will feature as payments to intangible capital. Or consider organizational capital, in particular, the internal processes by which a company, say Apple, manages its global supply chain. Although such knowledge may be created and applied by managers within Apple, even when those managers leave the firm, Apple retains a good part if not all of that knowledge. Of course that knowledge may decay in competitive value for other reasons (as the market power is temporary a la the model of section 1 and footnote 5). But the point is that the knowledge involved is, once again, a payment to the intangible capital of a firm (Apple) and not simply a dimension of human capital as conventionally defined.

\section{Harmonized estimates}

As previously noted, macroeconomic estimates of intangible investment for European countries were developed for the COINVEST and INNODRIVE projects, and by the Conference Board for its productivity and innovation program. The primary objective of these efforts was to more or less replicate the CHS methods. The task presented certain challenges, as the application of the model, its list of assets, and the data available for its parameterization are not necessarily the same on both sides of the Atlantic.

There are two types of empirical issues that need to be addressed before presenting the harmonized results. The first concern the temporal and industrial/sector coverage of the estimation and growth analysis. The second concern details for certain series that were changed to achieve harmonized estimates. The main advances in this respect are the 
inclusion of apprenticeship in training expenditure and the adoption of a cost based approach to calculate investment in new financial products.

Because the INNODRIVE project aimed for the broadest possible coverage, the 27 member states of the European Union plus Norway, we used that project's estimates of intangible investment and capital as a starting point. The INNODRIVE estimates are from 1995 to 2005.

\subsection{Coverage}

Depending on data availability, we produce harmonized time series of intangible investment for the EU27 member countries and Norway and the US in 1995-2005, and for the EU15 economies, the US plus Czech Republic and Slovenia we add the years 2006-2009. We retain 1995 as the initial year for estimation even though a longer time period would be preferred for the analysis of economic growth.

We set the EUKLEMS market sector as the boundary for our analysis, a scope that yields aggregate productivity estimates for an economy's profit-maximizing firms. As a practical matter, relative to INNODRIVE's earlier estimates, the move essentially meant the inclusion of agriculture; it also meant the exclusion of rental real estate, which EUKLEMS omits from its definition of the market sector due to measurement

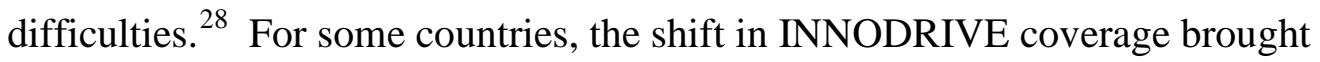
INNODRIVE estimates closer to COINVEST estimates while for others and the U.S., the move also meant the inclusion of agriculture, which for certain countries has a notable impact on the results. ${ }^{29}$

\subsection{Investment in training}

A review of the INNODRIVE measures for each asset revealed that an adjustment to the training subcomponent of organizational capital was needed. The adjustment was to include apprentice training; only vocational training was included in the original estimates. $^{30}$

\footnotetext{
${ }^{28}$ The market sector in EUKLEMS is NACE sectors A through $\mathrm{K}$ (excl. real estate) plus sectors $\mathrm{O}$ and $\mathrm{P}$. We exclude sector P (private households) and work with NACE sectors A through K (excl, real estate) plus sector $\mathrm{O}$.

${ }^{29}$ As is customary in the empirical analysis of European economic growth, the tangible asset boundary does not include land or inventories whereas statistics for the U.S. usually include them (see documentation and data on the US BLS website). For comparability with the EU, and as in van Ark et al. (2009), these assets have been excluded from the U.S. results reported in this paper.

${ }^{30}$ Janet Hao provided the analysis of this issue.
} 
The change is upward (figure 3) and essentially closes the gap between the INNODRIVE and Conference Board estimates (apart from the coverage issues just discussed). ${ }^{31}$ Apprenticeship is an important system for training skilled craft workers in some European countries, but it is not an important feature of the U.S. workplace, and costs of such systems were not mentioned in the CHS work. Zwick (2007) shows that apprenticeship programs generate returns to firms above and beyond wage and program costs, and on this basis, including apprentice training as investment in firm-specific human capital seems appropriate.

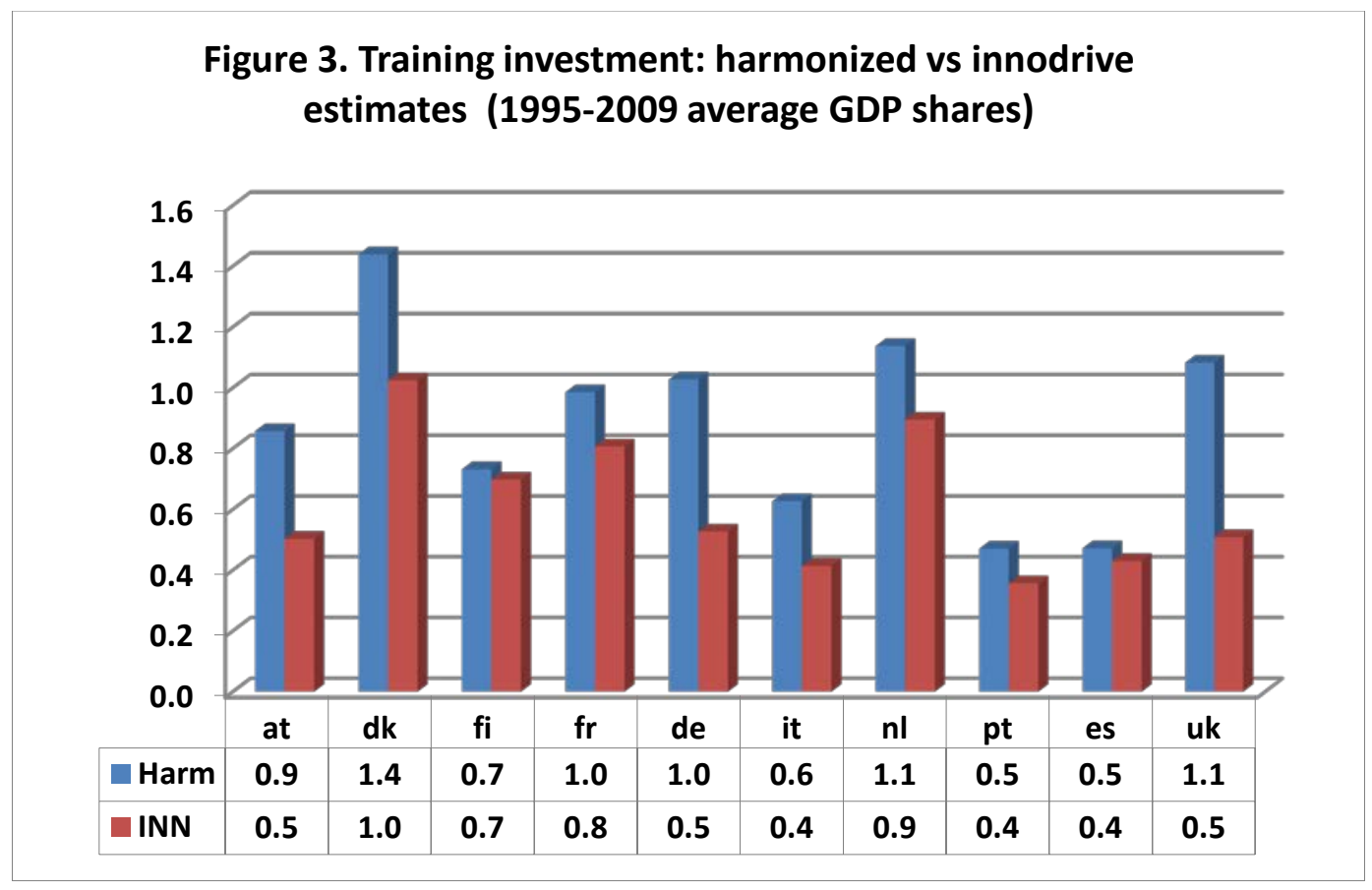

\subsection{Investments in new product development in financial services}

In this paper, we introduce a new method for estimating investment in new product development (NPD) in financial services industries. The topic was reviewed in work for the COINVEST project, but results for individual countries (France, Germany, and the UK) were extremely disparate and difficult to interpret. The general approach, however, was sound: to follow the approach of Hunt (2008) who argued that most of the cost of

\footnotetext{
${ }^{31}$ Although the new gaps are not shown, note that France and Germany show essentially the same propensity to invest in firm-specific human capital via training under the harmonized estimates and recall that Hao, Manole, and van Ark (2008), who included apprentice training in their estimates, reported a similar finding. The data source for the costs of apprentice training is the European Labor Cost Survey, the same source used by Hao et al. (2008).
} 
innovation in the financial service sector consists of compensation of researchers. In related work for the United States, Corrado and Hao (unpublished) used O*Net to study the work activities of detailed occupations. O*Net is a product of the U.S. Department of Labor in which detailed information is provided on the work activities and skill requirement for jobs. Corrado and Hao identified a group of occupations they called "quantitative finance” occupations that they added to STEM occupations to arrive at an estimate of employment and compensation of workers in financial services whose work activities touched on analytical problem-solving and/or innovation. We use their detailed compensation estimates to develop an estimate of investment in new financial products for the United States using a production cost approach.

\section{Table 3. Production cost estimates of investment in new product development (NPD) in} financial services industries in the United States

\begin{tabular}{|c|c|c|c|c|}
\hline & \multicolumn{2}{|c|}{$\begin{array}{l}\text { STEM occupations used to } \\
\text { derive NPD investment }\end{array}$} & \multirow[b]{2}{*}{$\begin{array}{c}+ \\
\text { Purchased } \\
\text { R\&D services }\end{array}$} & \multirow[b]{2}{*}{$\begin{array}{c}\text { - } \\
\text { Reported } \\
\text { R\&D }\end{array}$} \\
\hline & Traditional & $\begin{array}{c}+ \\
\text { Quantitative } \\
\text { finance and } \\
\text { STEM } \\
\text { managers }\end{array}$ & & \\
\hline & (1) & $(2)$ & (3) & (4) \\
\hline 1. Value in 2008 (US dollars) & 29,910 & 33,598 & 38,938 & 36,802 \\
\hline $\begin{array}{ll}\text { 2. Percent of high-skilled labor } \\
\text { compensation }^{1,2,3}\end{array}$ & & $\begin{array}{l}7.3 \\
(.5)\end{array}$ & $\begin{array}{l}8.3 \\
(.6)\end{array}$ & $\begin{array}{l}7.5 \\
(.5) \\
\end{array}$ \\
\hline $\begin{array}{l}\text { 3. Ratio of existing method to } \\
\text { production cost }^{1}\end{array}$ & 8.3 & 5.0 & 4.4 & 4.8 \\
\hline \multicolumn{5}{|c|}{$\begin{array}{l}\text { SOURCE-Time-series estimates of employment and compensation by industry and detailed professional } \\
\text { occupations as developed by Corrado and Hao (unpublished) using source data from the Bureau of Labor Statistics } \\
\text { (BLS) and the Bureau of Economic Analysis (BEA). } \\
\text { NoTE-These NPD estimates are based on } 50 \text { percent of the labor compensation of included occupations plus a } \\
\text { markup to account for materials use. The latter is based on an average of the materials share in BEA's R\&D satellite } \\
\text { account for financial services and the share in the computer systems design and related services industry (NAICS } \\
\text { 5415). More specific information on the columns is as follows: } \\
\text { Column } 1 \text { excludes the occupations used by BEA to estimate software investment. Traditional STEM occupations } \\
\text { are those in the sciences (life, physical, social), computer science, engineering, or mathematics. } \\
\text { Column } 2 \text { adds in STEM occupations defined by O*Net as needing a degree in a STEM field. This includes the } \\
\text { quantitative finance occupations (accountants, actuaries, statisticians, financial quantitative analysts, and risk } \\
\text { management specialists) and STEM managers. Only half of STEM managers are included in these NPD calculations. } \\
\text { Column } 3 \text { assumes purchased R\&D services by financial services industries are } 3.3 \text { percent of the total revenue of } \\
\text { the R\&D services industry (NAICS 5417), the share in BEA’s } 2002 \text { benchmark supply-use table. } \\
\text { Column } 4 \text { subtracts reported R\&D costs in the financial services industry. Data are from BEA's R\&D satellite } \\
\text { account, with the purchased component placed on a cost basis. } \\
\text { 1. 1995-2008 average value. } \\
\text { 2. High-skilled labor compensation is derived from the ratio in EUKLEMS for sector J. Estimates from } 1995 \text { on are } \\
\text { preliminary estimates from WIOD (forthcoming). } \\
\text { 3. Standard deviation in parentheses. }\end{array}$} \\
\hline
\end{tabular}


Some key steps in developing a production cost estimate of investment in new product development (NPD) in financial services industries using compensation data for selected occupations are shown in table 3. These NPD estimates are based on 50 percent of the labor compensation of included occupations plus a markup to account for materials use. Comparing columns 1 and 2 of the table shows that the impact of including the CorradoHao quantitative finance occupations is significant. When purchased $R \& D$ services are then added, we estimate that production costs of NPD investment in financial services is equal to about 8 percent of the compensation of high-skilled workers in the industry (1995 to 2008 average). The existing method, based on CHS (2005), is more than 4 times larger than the production cost estimate.

We use table 3's underlying time series for NPD for the US, and for the EU, we assume that 8 percent of compensation of high skilled workers is a good approximation for the innovation investment in financial industry. Figure 4 shows the GDP shares of investment in NPD for financial services estimated as in CHS (2005)_labeled “old"compared with the production cost approach incorporated into the harmonized estimates presented in this paper-labeled "new". The new harmonized estimates are revised downwards, and revisions vary considerably across countries.

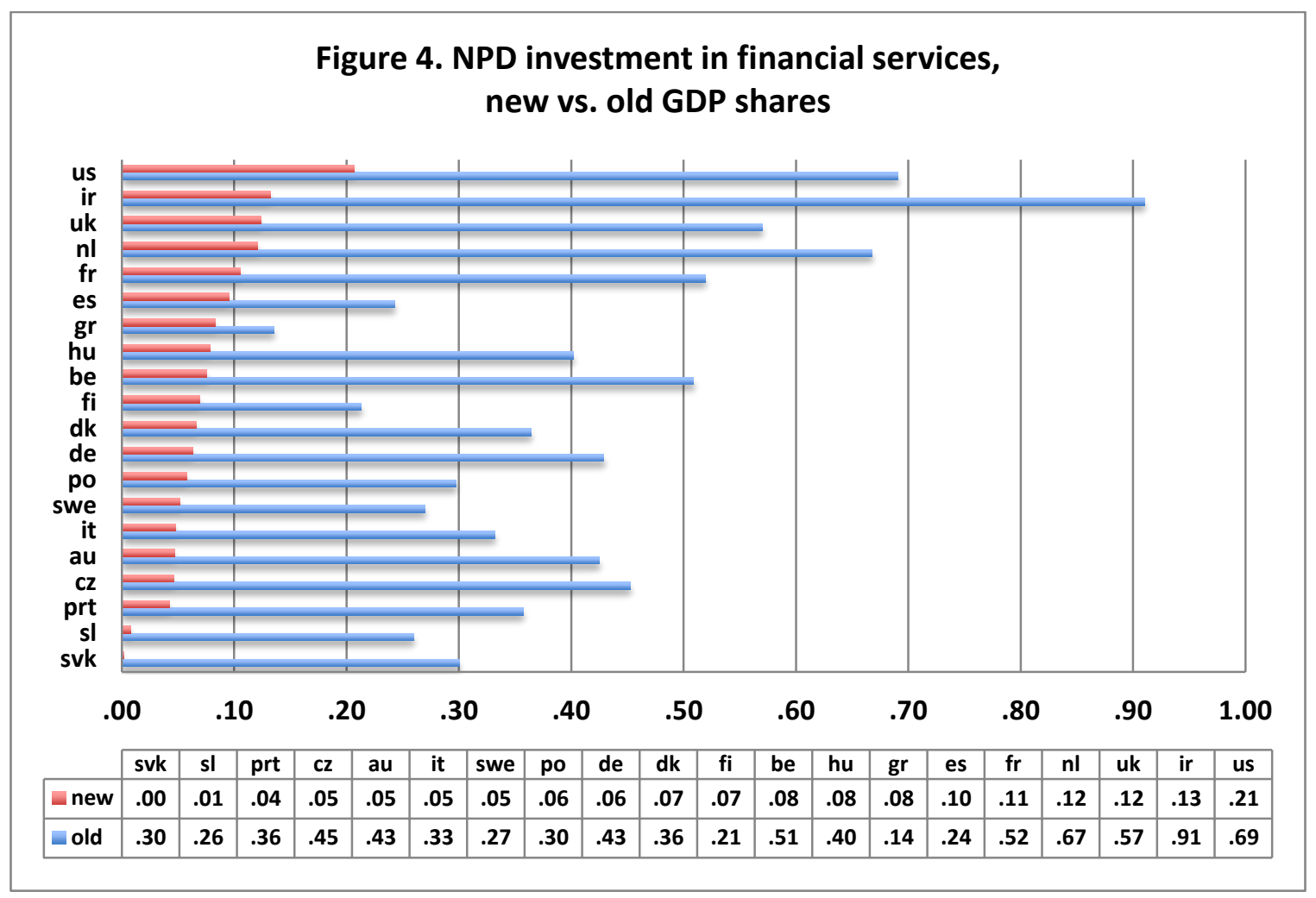


Although this change in methods has a large impact on this component of intangibles, the original NPD estimates for financial services were a relatively small component of the overall scheme (see data table in figure), and thus the change does not have a material impact on the overall estimates of EU or US intangibles.

\section{$\underline{4.3 \text { Results }}$}

The updated evidence on intangible investment by the market sector in the EU15 area and in its main groups of member countries from 2005 to 2009 is shown in Figure 5. As previously found (Jona-Lasinio et al. 2011; see also van Ark et al. 2009), the EU15 shows a lower propensity to invest in intangibles than does the United States. The rates for the U.S., however, are essentially the same as those for the UK, whose propensity to invest in intangibles is the highest in Europe, and like the United States, invests more in intangibles than it does in tangibles.

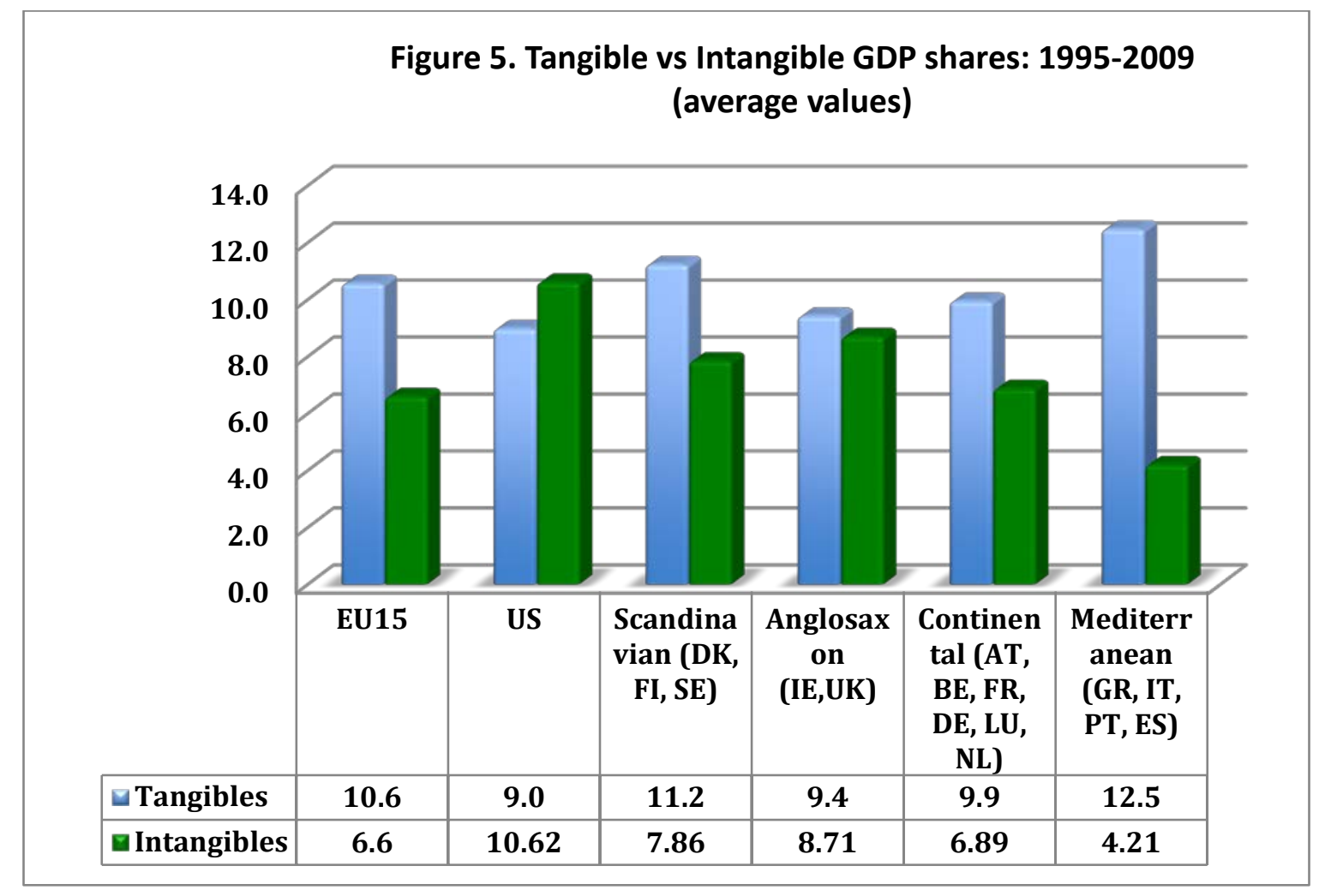

To understand a bit of the dynamics that underlie these cross country differences, the percent change in tangible and intangible investment rates from 1995 to 2007 is shown in the Figure 6. The rate of intangible investment in all EU15 regions increased from 1995 to 2007 while the rate of tangible investment fell or remained about flat. (The Mediterranean region is an exception, however.) In the Anglosaxon countries (an 
Figure 6. Tangible vs Intangible GDP shares: 1995-2007

(percentage changes)

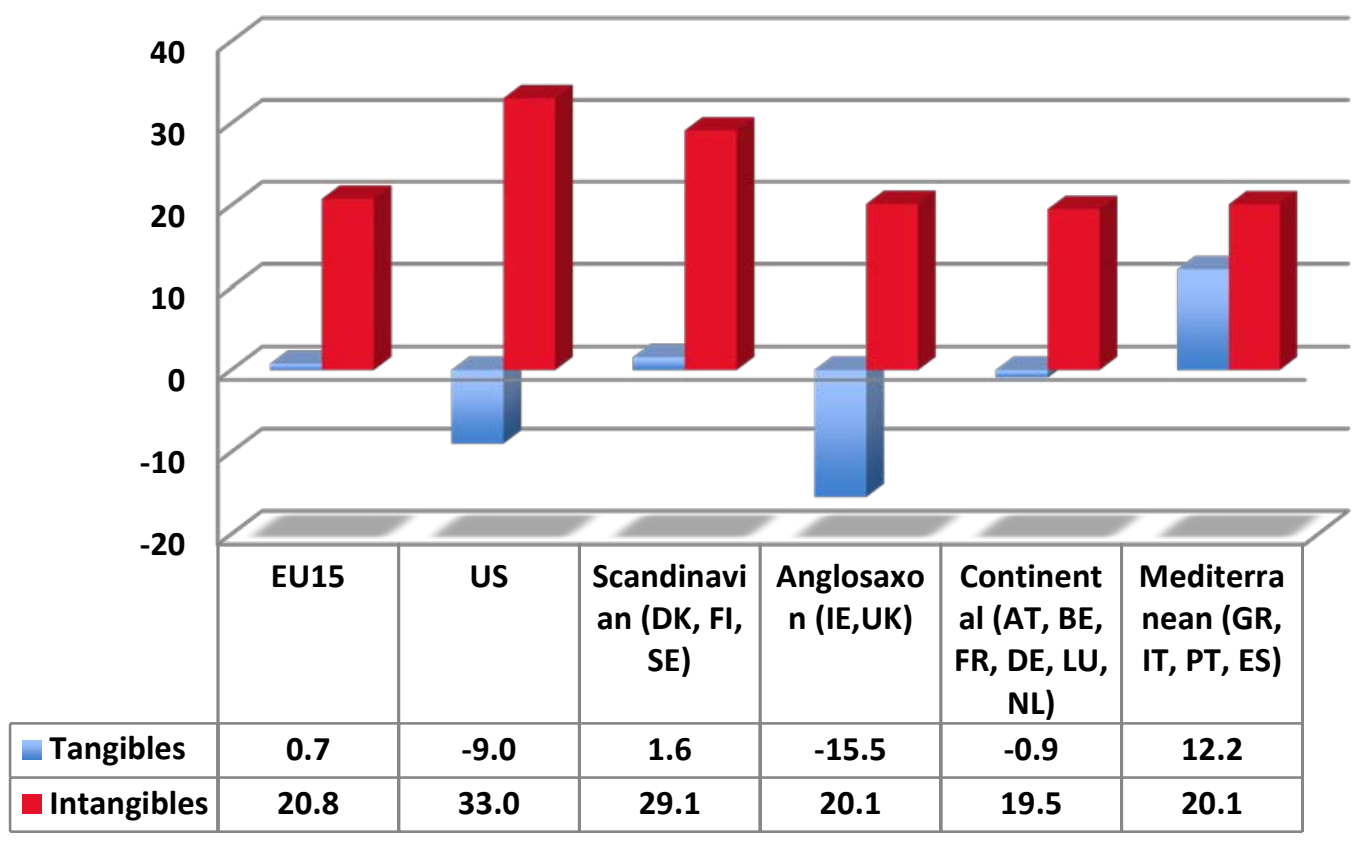

Figure 7. Tangible vs Intangible GDP shares: 2007-2009 (percentage changes)

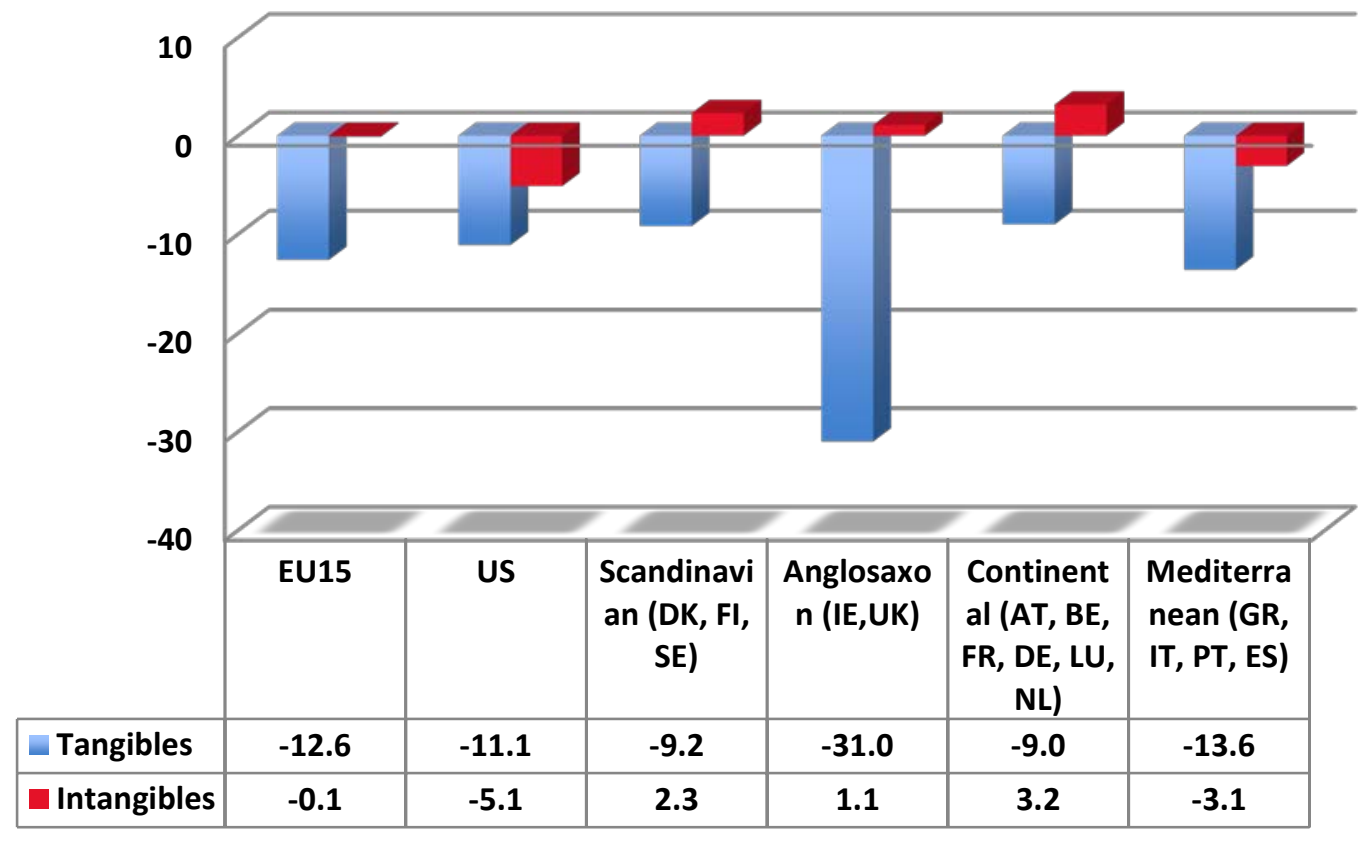


aggregate dominated by the UK), the slowdown in tangible investment is especially pronounced and is comparable to the US.

The more recent data show that the rate of tangible investment in the EU15 declined sharply from 2007 to 2009 while the rate of intangible investment remained about flat. In the US, intangible investment fell. Across Europe there are small differences by regions, and intangible investment relative to tangibles held up better in recent years on both continents. All told, the shift to intangible investment from 1995 to 2009 is a striking trend.

The composition of intangible investment varies substantially across countries. The main change in moving from the May 2011 INNODRIVE estimates to the harmonized estimates in this paper is to increase the importance of organizational capital and decrease the relevance of new financial products. But on the whole, the updated results present the same picture of heterogeneity across Europe as described in van Ark et al. (2009).

\section{Growth results: multiple strategies, consistent results}

The growth analysis has been expanded and improved with the harmonization. We currently are able to present a sources-of-growth analysis for 14 EU countries: Austria, Belgium, Czech Republic, Denmark, Finland, France, Germany, Ireland, Italy, Netherlands, Solvenia, Spain, Sweden, and United Kingdom. Relative to INNODRIVE's previous results, the estimates for Belgium, the Czech Republic and Solvenia are new. The new estimates stems in large part from work developed under COINVEST.

Table 4 below reports our main results. In addition to the features of the harmonization that have been discussed, relative to the results in Jona-Lasinio, Iommi, and Roth (2001), software has been deflated by the harmonized deflator described in section 3.3, and we also have included the contribution from changes in labor composition (from EUKLEMS and WIOD). Of course, the first result seen in table 4 is the finding originally reported in CHS, that once intangibles have been capitalized, capital deepening (column 2) becomes the dominant source of growth (cf. column 2 with columns 5 and 6).

The second result, summarized in the memo items, is that intangible capital deepening accounts for one-fifth to one-third of the growth of labor productivity. For the United States, where we have a relatively long time-series (on a EU comparability basis, from 1977 to 2010), the fraction for the sub-period in table 1 is essentially the same as the

fraction for the entire period. That finding would, of course, not necessarily hold for 
other countries, nor for that matter, for U.S. experience in earlier time periods, but it is useful to note it nonetheless.

The third and final point is a twist on the former. On a country-by-country basis (the main portion of the table), the contribution of intangible capital in some large European countries (e.g., Germany, Italy, and Spain) is lower than in the UK and the US as found in van Ark et al. (2009). But as the memo item shows, the inclusion of more countries from INNODRIVE (in particular, the Scandinavian countries) and additional years of data reveal a more consistent picture of the relative importance of the sources of growth across countries.

Table 4. Contributions to the growth of output per hour, 1995 to 2007

\begin{tabular}{|c|c|c|c|c|c|c|}
\hline & \multirow{2}{*}{$\begin{array}{l}\text { Labor } \\
\text { productivity } \\
\text { growth }\end{array}$} & \multicolumn{5}{|c|}{ Contribution of components: } \\
\hline & & $\begin{array}{l}\text { Total Capital } \\
\text { Deepening }\end{array}$ & Tangibles & Intangibles & $\begin{array}{c}\text { Labor } \\
\text { Composition }\end{array}$ & $\begin{array}{l}\text { Multifactor } \\
\text { productivity }\end{array}$ \\
\hline & (1) & (2) & (3) & (4) & (5) & (6) \\
\hline Austria & 2.4 & 0.8 & .3 & .5 & .2 & 1.4 \\
\hline Belgium & 1.8 & 0.7 & .2 & .5 & .1 & .9 \\
\hline Czech Republic & 4.2 & 2.4 & 1.9 & .5 & .3 & 1.5 \\
\hline Denmark & 1.4 & 1.2 & .7 & .5 & .2 & -.1 \\
\hline Finland & 3.8 & .9 & .2 & .7 & .2 & 2.6 \\
\hline France & 1.9 & 1.0 & .4 & .6 & .4 & .4 \\
\hline Germany & 1.7 & 1.0 & .7 & .3 & .0 & .7 \\
\hline Ireland & 3.8 & 1.4 & .8 & .6 & .1 & 2.2 \\
\hline Italy & .6 & .7 & .5 & .2 & .2 & -.4 \\
\hline Netherlands & 2.3 & .9 & .4 & .5 & .4 & 1.0 \\
\hline Slovenia & 5.3 & 1.7 & 1.2 & .5 & .7 & 2.8 \\
\hline Spain & .8 & 1.0 & .7 & .3 & .5 & -.6 \\
\hline $\begin{array}{l}\text { Sweden } \\
\text { United }\end{array}$ & 3.7 & 1.9 & 1.1 & .8 & .3 & 1.4 \\
\hline Kingdom & 2.9 & 1.5 & .8 & .7 & .4 & 1.1 \\
\hline United States & 2.7 & 1.7 & .8 & .9 & .2 & .8 \\
\hline Memos & & \multicolumn{5}{|c|}{ Average percent contribution of component: } \\
\hline EU countries & & 47.0 & 27.1 & 19.9 & 11.0 & 42.0 \\
\hline US & & 64.5 & 30.8 & 33.7 & 6.0 & 29.5 \\
\hline
\end{tabular}

Source: Authors' calculations based on intangible investment databases developed by the authors and/or partners in previous works. See text for further discussion.

Note-For individual countries, figures in column (1) are annual percent changes, and figures in columns (2) through (6) are percentage points. 
Despite this similarity, there are significant differences in the deployment of intangibles by broad type across countries, however, and these are displayed for a sample of countries in Figure 8. This shows that the divergent patterns found in previous work persist in the harmonized estimates and underscores that multiple strategies can be used to exploit the knowledge base of a region or a country to promote its economic growth. In any event, it would appear that encouraging investment in intangibles is a way to develop and/or sustain a country’s competitive advantage.

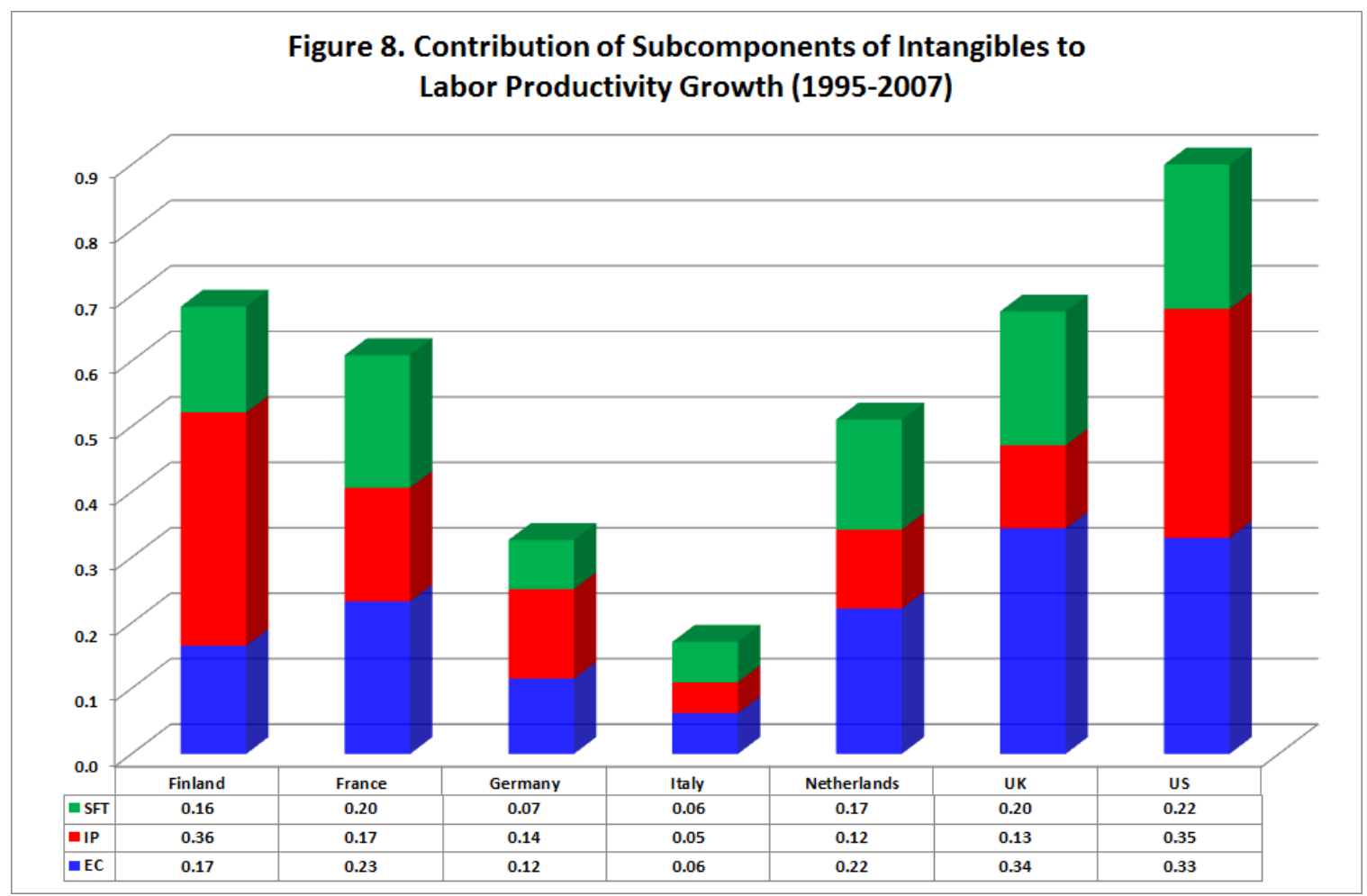

\section{Concluding thoughts and next steps}

This paper has set out methods, presented data and analyzed investment and sources of economic growth including intangibles for the European Union and the United States. Our data for investment cover the EU27 member countries and the US in 1995-2005, and for the EU15 economies, the US plus Czech Republic and Slovenia we add the years 2006-2009. Our growth accounting covered 14 EU countries plus the US.

Despite the emerging parity in the contribution of intangible capital to European growth, for some countries in Europe, this stands against a backdrop of smaller rates of growth of labor productivity than typically experienced in the UK and US. And in most cases the shortfall can be attributed to lower multifactor productivity growth. This could result from structural factors orthogonal to intangible capital per se, such as a greater ability to 
obtain financing for innovation in certain countries. It also could be associated with returns to scale or intangible capital deepening itself, as suggested by Figure 9, which shows a positive association between MFP growth and the contribution of intangible capital deepening (and one that is much stronger than that for tangible capital, figure 10).

Figure 9 - Intangible Capital and Spillover Effects

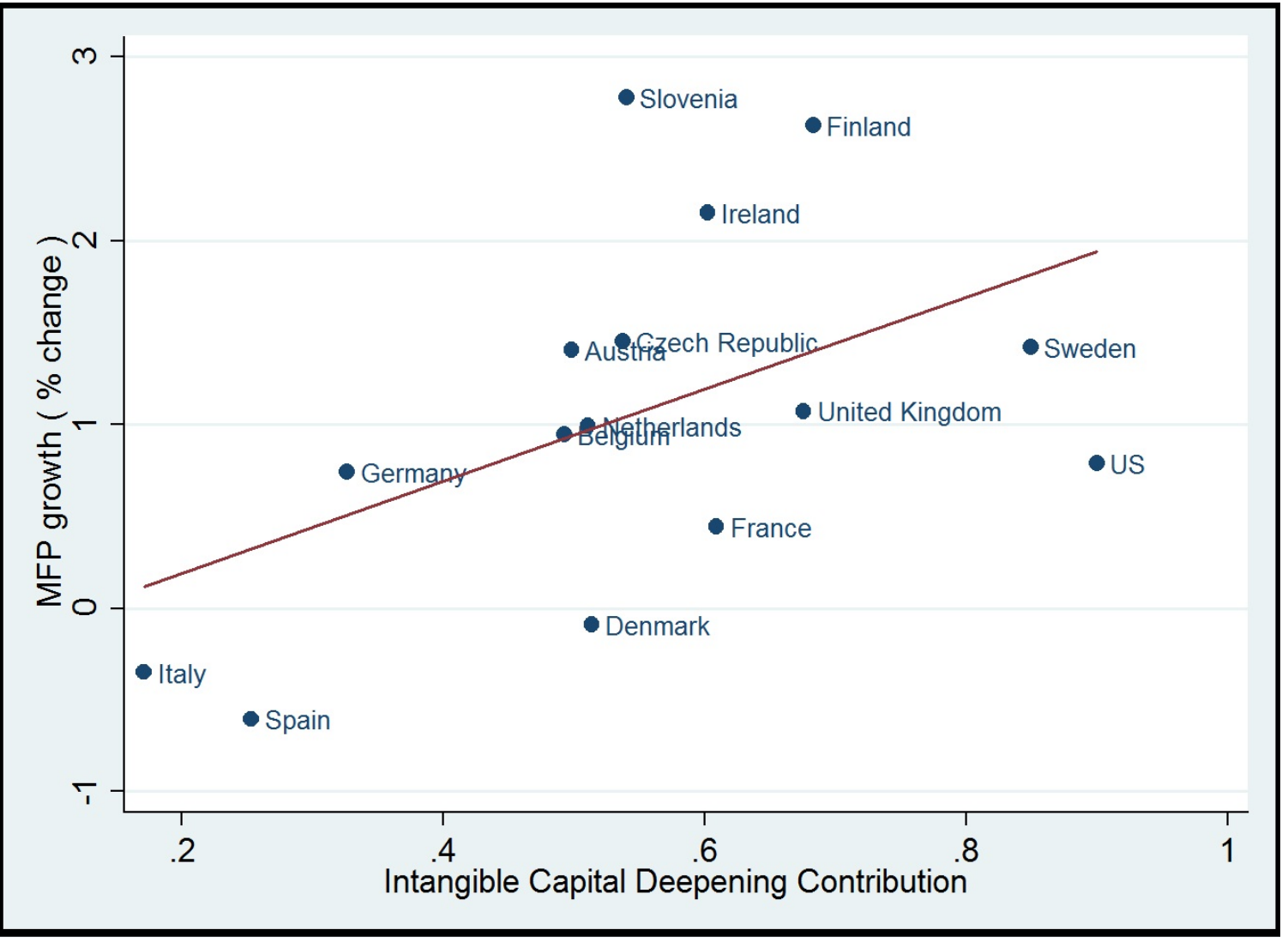

We are, of course, conditioned to think in terms of spillovers from R\&D because the topic is well researched, but spillovers occur whenever an investment in innovation by a firm or an industry creates a platform that spurs follow on innovations and new or expanded markets (think “apps” for mobile phones, or the "clusters" that form around a successful business). To better understand the spillovers that are suggested by Figure 5 suggests deeper study of the returns to specific intangible assets and channels through which the returns accrue. With the advent of the IT revolution and Internet technology, the spillover channels may be quite different than the "distance" models formulated and studied by Zvi Griliches some time ago (see Griliches 1992 for a review). A deeper dive into such topics is the subject of a forthcoming companion paper (Corrado, Haskel, JonaLasinio 2012) 
Figure 10 - Tangible Capital and Spillover Effects

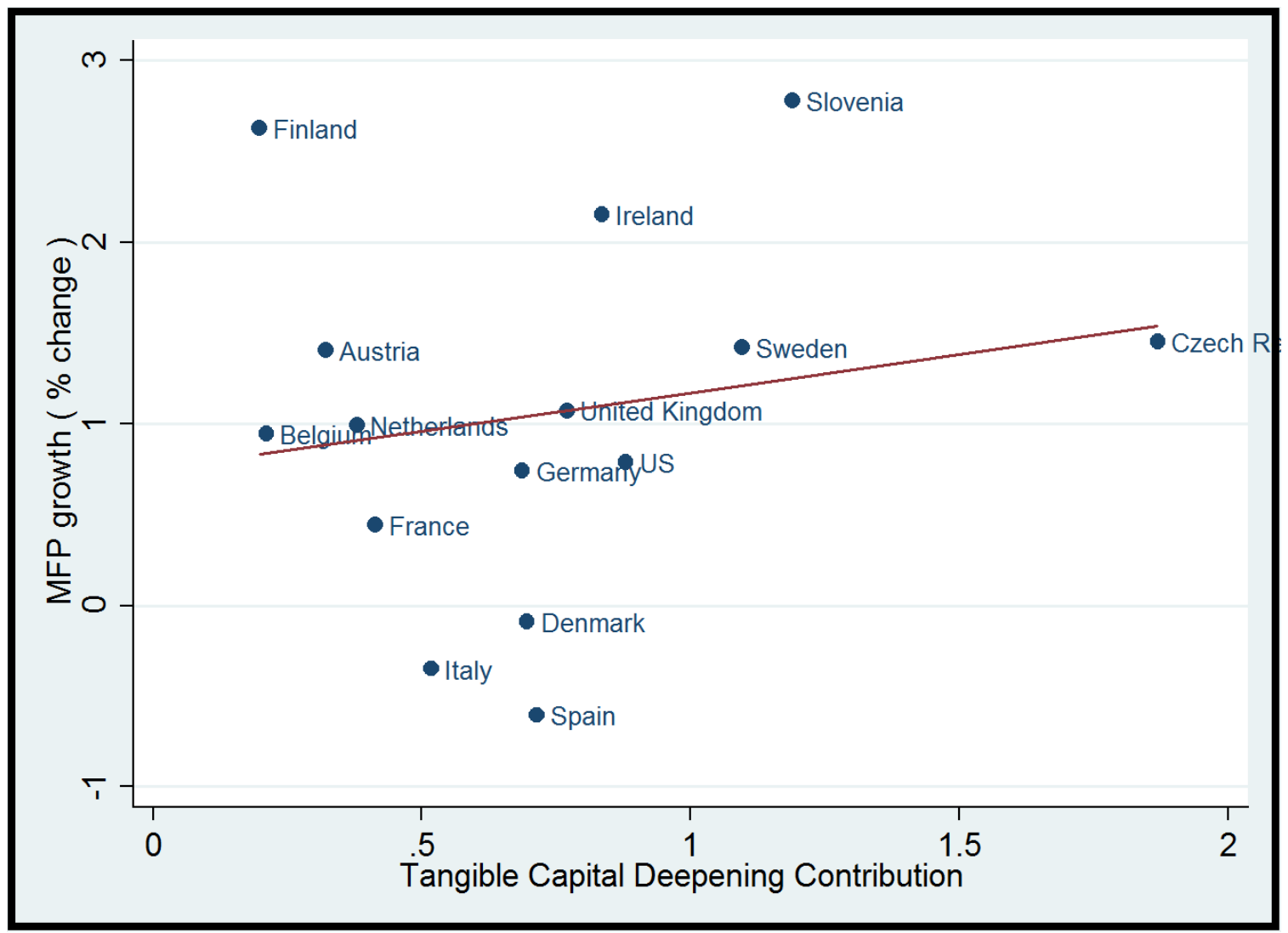

The harmonized estimates of intangible capital for Europe introduced in this paper are preliminary, but key advances were made that substantially enhance their usefulness in policy discussions. The new growth accounting results are the broadest available results for Europe to date. Although Europe invests less in intangibles than the US, intangibles account still account for between 1/5 and 1/4 of the average growth of market sector labor productivity in Europe. In addition to improved measurement, advanced countries need to build a deeper understanding of the returns to intangible assets and of the role intangibles play in the national and international innovation diffusion process. 


\section{References}

Abramovitz, Moses (1956). "Resource and Output Trends in the U.S. since 1870.” American Economic Review 46:2 (May), 5-23.

Aizcorbe, Ana M., Carol E. Moylan, and Carol A. Robbins (2009). “Toward Better Measurement of Innovation and Intangibles” Survey of Current Business 89 (January): 10-23.

Awano, Gaganan, Mark Franklin, Jonathan Haskel, and Zafeira Kastrinaki (2010). "Investing in Innovation: Findings from the UK Investment in Intangible Assets Survey.” NESTA Index Report (July).

Barnes, Paula (2010). “Investment in Intanagible Assets and Australia’s Productivity Growth-Sectoral Estimates.” Productivity Commission Staff Working Paper.

Chamberlin G. Chesson A. Clayton T. and Farooqui S. (2006). Survey-based measures of software investment in the UK. Economic Trends, No. 627 (February).

Copeland, Adam M., Gabriel W. Medeiros, and Carol A. Robbins (2007). "Estimating Prices for R\&D Investment in the 2007 R\&D Satellite Account.” BEA paper (November).

Corrado, Carol, Charles Hulten, and Daniel Sichel (2005). "Measuring Capital and Technology.” In Measuring Capital in the New Economy, C. Corrado, J. Haltiwanger, and D. Sichel, eds., Studies in Income and Wealth, Vol. 65, 11-14. Chicago: The University of Chicago Press.

Corrado, Carol, Charles Hulten and Daniel Sichel (2009). “Intangible Capital and US Economic Growth.” The Review of Income and Wealth 55: 3 (September), 661685.

Corrado, Carol and Charles Hulten (2010). "How Do You Measure a_Technological Revolution“?” American Economic Review 100:5 (May), 99-104.

Corrado, Carol, Peter Goodridge, and Jonathan Haskel (2011). “Constructing a Price Deflator for R\&D: Estimating the Price of Knowledge as a Residual.” The Conference Board Economics Program Working Paper EPWP \#11-03.

Dal Borgo, Mariela, Peter Goodridge, Jonathan Haskel and Annarosa Pesole (2011). Productivity and growth in UK industries: an intangible investment approach, 2011-06, Imperial College Business School, https://spiral.imperial.ac.uk:8443/bitstream/10044/1/9027/1/Haskel\%20201106.pdf

Dougherty, Sean M, Robert Inklaar, Robert H. McGuckin, and Bart van Ark (2007). "International Comparisons of R\&D Expenditure: Does an R\&D PPP Make a Difference?” In Hard-to-Measure Goods and Services, Essays in Honor of Zvi 
Griliches, E. R. Berndt and C. R. Hulten, eds., Studies in Income and Wealth, vol. 67, 291-322.

Fukao, Kyoji, Tsutomu Miyagawa, Kentaro Mukai, Yukio Shinoda, and Konomi Tonogi (2009). "Intangible Investment in Japan: Measurement and Contribution to Growth” Review of Income and Wealth 55:3 (September), 717-736.

Galindo-Rueda, F. (2007). "Developing an R\&D Satellite Account for the UK: A Preliminary Analysis.” Economic \& Labour Market Review, vol. 1:12, 18-29.

Griliches, Zvi. 1957. "Hybrid Corn: An Exploration in the Economics of Technological Change” Econometrica 25 (October): 501-522.

Griliches, Zvi (1992). “The Search for R\&D Spillovers.” Scandinavian Journal of Economics 94, Supplement, 29-47.

Hall, Robert E. (2000). “e-Capital: The Link between the Stock Market and the Labor Market in the 1990s,” Brookings Papers on Economic Activity, 2, 73-118. (2001a). “Struggling to Understand the Stock Market,” American Economic Review Papers and Proceedings, 91:5 (May), 1-11.

(2001b). “The Stock Market and Capital Accumulation,” American Economic Review, 91, 1185-202.

Hulten, Charles R., “On the 'Importance' of Productivity Change,” American Economic Review, 69, 126-36, 1979.

— - "Total Factor Productivity: A Short Biography,” in New Developments in Productivity Analysis, Studies in Income and Wealth, Volume 65, University of Chicago Press, Chicago, 2001.

Hulten, Charles R. and Frank C. Wykoff (1981). "The Estimation of Economic Depreciation Using Vintage Asset Prices,” Journal of Econometrics, 15, 367-96.

Jona-Lasinio, Cecilia, Massimiliano Iommi, and Felix Roth (2011). "National Measures of Intangible Capital I EU27 and Norway”, in H. Piekkola (ed.), “Intangible Capital-Driver of Growth in Europe.”

Jona-Lasinio, Cecilia (2011). “INNODRIVE and COINVEST.”

Marrano, Mauro Giorgio, Jonathan Haskel and Gavin Wallis (2009): What happened to the knowledge economy? ICT, intangible investment and Britain $s$ productivity record revisited. The Review of Income and Wealth 55: 3 (September), 686-716.

McGrattan, Ellen and Edward C. Prescott, “Is the Stock Market Overvalued?” Quarterly Review, Federal Reserve Bank of Minneapolis, 24(4), 20-40, 2000. 
Mead, Charles Ian (2007). "R\&D Depreciation Rates in the 2007 R\&D Satellite Account.” BEA BEA/NSF 2007 R\&D Satellite Account Background Paper (November).

Mokyr, Joel, 2005. "Long-Term Economic Growth and the History of Technology," in: Philippe Aghion \& Steven Durlauf (ed.), edition 1, volume 1, chapter 17, pages 1113-1180 Elsevier.

Moylan, Carol and Carol Robbins (2007). "Research and Development Satellite Account Update.” Survey of Current Business 87 (October): 49-92.

O’Mahony, Mary and Marcel P. Timmer (2009). “Output, Input and Productivity Measures at the Industry Level: the EU KLEMS Database", Economic Journal, 119 (538), pp. F374-F403.

Oulton, Nicholas (2002). "ICT and Productivity Growth in the United Kingdom," Oxford Review of Economic Policy, Oxford University Press, vol. 18(3), pages 363-379.

Oulton Nicholas. and Sally Srinivasan (2003). "Capital Stocks, Capital Services, and Depreciation: an integrated framework" Bank of England, Working Paper no. 192.

Pakes, Ariel, and Mark Schankerman (1984). "The Rate of Obsolescence of Patents, Research Gestation Lags, and the Private Rate of Return to Research Resources." In $R \& D$, Patents, and Productivity, ed. Zvi Griliches, 73-88. Chicago: University of Chicago Press.

Piekkola, Hannu et al. (2011) "Firm-level Intangible Capital in Six Countries: Finland, Norway, the UK, Germany, The Czech Republic and Slovenia.” In H. Piekkola (ed), "Intangible Capital - Driver of Growth in Europe."

Romer, Paul M. (1990). “Endogenous Technological Change.” Journal of Political Economy, Vol. 98:5 (October), Part 2: S71-S102.

Rotemberg, Julio J. and Michael Woodford (1995). "Dynamic General Equilibrium Models with Imperfectly Competitive Product Markets.” In Frontiers of Business Cycle Research, Thomas F. Cooley, ed., 243-293. Princeton: Princeton University Press.

Soloveichik, Rachel (2010). “Artistic Originals as a Capital Asset.” American Economic Review 100:5 (May), 110-114.

System of National Accounts 2008. European Commission, International Monetary Fund, OECD, United Nations, World Bank.

Timmer, Marcel (2012), ed., "The World Input-Output Database (WIOD): Contents, Methods and Sources." (April, Version 0.9) available at www.wiod.org.

U.K. Competition Commission (2006), Home Credit Inquiry, 
http://webarchive.nationalarchives.gov.uk/+/http://www.competitioncommission.org.uk/inquiries/current/homecredit/

U.S. Internal Revenue Service, Publication 535: Business Expenses. http://www.irs.gov/pub/irs-pdf/p535.pdf

van Ark, Bart, Janet X. Hao, Carol A. Corrado, and Charles R. Hulten. 2009. "Measuring Intangible Capital and its Contribution to Economic Growth in Europe." European Investment Bank Papers, 14(1), 62-93.

van Ark, Bart and Kirsten Jaeger (2010). "Intangible Capital in Europe and its Implications for Future Growth. The Conference Board.

Weitzman, Martin L., "On the Welfare Significance of National Product in a Dynamic Economy,” Quarterly Journal of Economics, 90, 156-62, 1976.

Zwick, Thomas (2007). “Apprenticeship training in Germany - investment or productivity driven?” ZEW Discussion Paper No. 07-023 (April). 


\title{
Methodological Notes - Harmonized Database
}

\author{
Carol Corrado (The Conference Board, New York) \\ Jonathan Haskel (Imperial College, CEPR and IZA), London \\ Cecilia Jona-Lasinio (ISTAT and LUISS), Rome \\ Massimiliano Iommi (ISTAT and LUISS), Rome
}

\section{Introduction}

In this note we report a short summary of the data sources and estimation methods used to produce the harmonized estimates of nominal investment in intangible assets as described in Corrado, Haskel, Jona-Lasinio and Iommi (2012).

The main advancements with respect to the INNODRIVE-COINVEST-TCB estimates of intangible gross fixed capital formation are the inclusion of apprenticeship in training expenditure and the adoption of a cost based approach to calculate New Financial Product Development investment. Compared to the INNODRIVECOINVEST-TCB data, the harmonized estimates are both a methodological improvement and an update of existing time series of intangible gross fixed capital formation. Apart from training and NFPD, the sources and methods adopted to measure intangible investment can differ as to the time period according to data availability. Accordingly, also the country coverage can be different depending on the time period. The harmonized estimates cover the EU27 member countries and the US in 1995-2005, while they refer to the EU15 economies, the US plus Czech Republic and Slovenia for the years 2006-2009.

\section{$\underline{\text { 2. Data sources and estimation methods }}$}

\subsection{Organizational Structure (own-account component)}

\section{Data sources}

1) Structure of Earnings Survey

- $\quad$ SES represents EU-wide, harmonised structural data on gross earnings, hours paid and annual days of paid holiday leave that are collected every four years.

- Years available from Eurostat's website: The Eurostat website provides data only for the 2002 survey. Results for the year 2006 are available only for few countries.

- Variable of interest for our estimates: Mean annual earnings by profession.

2) Labour Force Survey 
- It is the main source of information about the situation and trends in the labour market in the EU. The survey's target population is all persons in private households aged 15 years or older.

- Data for all member states are mostly available from 1999 or 2000 onwards. Data relating to the former EU-15 are available from 1995 onwards. Data relating to the former EU-12 are available from 1987 onwards. Results for the candidate countries date back to 2002 and for the EFTA countries to 1995.

- Variable of interest for our estimates: Number of employees by occupation.

\section{Estimation method}

- Estimate the gross earnings of managers and gross earnings of all employees by multiplying the mean annual earnings (from the SES) for the number of employees (from the LFS).

- Calculate the share of gross earnings of managers as manager_comp_share = Gross earnings of managers / Gross earnings of all employees .

- $\quad$ Estimate the total expenditure for management compensation consistent with national accounts data by applying the share of gross earnings of managers to the total compensation of employees:

manager_comp $=$ manager_comp_share $*$ Compensation of employees (from National Accounts).

- Make an assumption about what proportion of spending is to be considered investment (inv_share). Following Corrado, Hulten and Sichel (2005), we have assumed inv_share $=20 \%$.

- Estimate the value of own-account investment in the organisational structure (own_organiz_structure) by applying the investment share to the total manager's compensation:

own_organiz_structure $=$ manager_comp $*$ inv_share .

\section{Estimation method for the years not covered by the survey}

Since for the time being only the 2002 SES is available, we have held manager_comp_share constant to the value for the year 2002 .

\subsubsection{0rganizational Structure (purchased component)}

The purchased component has been estimated using the nominal gross output of the NACE 2002 version of industry "7414 - Business and management consultancy activities".

No countries release national accounts estimates of the gross output of NACE 7414. We try to produce estimates of gross output of industry 7414 consistent with national account data. 


\section{$\underline{\text { Data sources }}$}

1) The data sources are annual Structural Business Statistics (we have integrated the Eurostat database with data provided by National Statistical Institutes and by institutions participating to the INNODRIVE project).

Table SS reports, for each country and year, if data from Structural Business Statistics (SBS) are available or not.

Table SS. Availability of data from Structural business Surveys for NACE 7414

\begin{tabular}{|c|c|c|c|c|c|c|c|c|c|c|c|}
\hline & 1995 & 1996 & 1997 & 1998 & 1999 & 2000 & 2001 & 2002 & 2003 & 2004 & 2005 \\
\hline Austria & - & - & sbs & sbs & sbs & sbs & sbs & sbs & sbs & sbs & sbs \\
\hline Belgium & - & - & - & - & - & sbs & sbs & sbs & sbs & sbs & sbs \\
\hline Bulgaria & - & - & - & - & - & - & sbs & sbs & sbs & sbs & sbs \\
\hline Cyprus & sbs & sbs & sbs & sbs & sbs & sbs & sbs & sbs & sbs & sbs & sbs \\
\hline Czech Republic & - & - & - & - & - & sbs & sbs & sbs & sbs & sbs & sbs \\
\hline Denmark & - & - & - & - & - & - & sbs & - & sbs & sbs & sbs \\
\hline Estonia & - & - & - & - & - & sbs & sbs & sbs & sbs & sbs & sbs \\
\hline Finland & sbs & sbs & sbs & sbs & sbs & sbs & sbs & sbs & sbs & sbs & sbs \\
\hline France & - & sbs & sbs & sbs & sbs & sbs & sbs & sbs & sbs & sbs & sbs \\
\hline Germany & sbs & sbs & sbs & sbs & sbs & sbs & sbs & sbs & sbs & sbs & sbs \\
\hline Greece & - & - & - & - & - & - & - & - & - & sbs & - \\
\hline Hungary & - & - & - & - & - & - & sbs & sbs & sbs & sbs & sbs \\
\hline Ireland & - & - & - & - & - & sbs & sbs & sbs & sbs & sbs & sbs \\
\hline Italy & - & - & sbs & sbs & sbs & sbs & sbs & sbs & sbs & sbs & sbs \\
\hline Latvia & - & - & - & - & - & - & - & - & sbs & sbs & - \\
\hline Lithuania & - & - & - & - & - & sbs & sbs & sbs & sbs & sbs & sbs \\
\hline Luxembourg & - & - & - & - & - & - & - & - & sbs & - & - \\
\hline Malta & - & - & - & - & - & - & - & - & - & sbs & - \\
\hline Netherlands & - & sbs & sbs & sbs & sbs & - & - & - & - & - & sbs \\
\hline Poland & - & - & - & - & - & - & - & - & sbs & - & - \\
\hline Portugal & - & - & - & - & - & - & sbs & - & - & sbs & sbs \\
\hline Romania & - & - & - & - & - & - & - & - & - & sbs & sbs \\
\hline Slovakia & - & - & - & - & - & sbs & sbs & sbs & sbs & sbs & sbs \\
\hline Slovenia & sbs & sbs & sbs & sbs & sbs & sbs & sbs & sbs & sbs & sbs & sbs \\
\hline Spain & - & - & - & - & - & - & sbs & sbs & sbs & sbs & sbs \\
\hline Sweden & - & - & sbs & sbs & sbs & sbs & sbs & sbs & sbs & sbs & sbs \\
\hline United Kingdom & sbs & sbs & sbs & sbs & sbs & sbs & sbs & sbs & sbs & sbs & sbs \\
\hline Norway & - & sbs & sbs & sbs & sbs & sbs & sbs & sbs & sbs & sbs & sbs \\
\hline
\end{tabular}




\section{Estimation method}

1. Calculate the share of turnover of industry 7414 in the turnover of industry 74 from survey data (Structural Business Statistics):

NACE7414_share $=$ NACE7414_turnover $/$ NACE74_turnover.

2. Estimate the gross output of NACE 7414 consistent with the national accounts by applying the share to gross output of industry 74 from the national accounts:

NACE7414_output $=$ NACE7414_share $*$ NACE74_output.

3. Estimate the share of turnover of NACE 7414 purchased by the business sector (NACE7110_enterprise_share) from the data disaggregated by client type (information available from both the Structural Business Statistics on Business Services and the FEACO survey).

4. Estimate the business sector expenditure on organisational structure as organiz_structure_expenditure = NACE7410_enterprise_share* NACE7414_output.

5. Make an assumption about what proportion of spending is to be considered investment (inv_share). Following Corrado, Hulten and Sichel, we have assumed inv_share $=80 \%$.

6. Estimate the value of investment in organisational structure (purch_organiz_structure) by applying the investment share to the total manager's compensation:

purch_organiz_structure= organiz_structure_expenditure $*$ inv_share.

Estimation method for the years not covered by the surveys

We have either interpolated NACE7414_share to fill holes between two years or we have it constant to the last value available.

Estimation method for the years 2006-2009

For the years 2006-2007 we have replicated the same sources and method we have used to estimate 1995-2005. In the year 2008 there is a break in SBS data: starting from 2008 SBS data are released according to NACE Rev2 classification. For this reason we cannot replicate the same method we have used for the previous years nor using SBS data to calculate an indicator of the change 2008/2007 to estimate 2008. In order to have a consistent indicator of the variation 2008/2007 we have updated NACE7414_turnover and NACE74_turnover using indeces of turnover (of the industry "Legal, accounting and management consultancy activities" and "Professional, scientific and technical activities required by STS Regulation", respectively). For the year 2009 we have updated purch_organiz_structure using the change 2009/2008 of the turnover of the industry "Business and other management consultancy activities" from SBS (Nace Rev2) surveys. When SBS data are not available we have estimated the change 2009/2008 from FEACO survey (for 
Denmark, Greece, Ireland and Spain) of from national accounts data on output of the industry "Legal and accounting activities; activities of head offices; management consultancy activities" (Nace Rev2) (Czech Republic).

\subsection{Firm-specific human capital}

Total investment in Firm Specific Human Capital is obtained as the sum of investment in vocational training and investment apprenticeships.

\section{“Vocational Training"}

\section{Data source}

Continuing Vocational Training Survey (CVTS)

- In our opinion, this source is to be preferred to national sources because it provides comparable statistical data on enterprise training across countries

- Expenditure for apprentice training is not included

- Years available from Eurostat's website: 1999 (CVTS2) and 2005 (CVTS3, still preliminary and incomplete).

- Industry detail: Data are available for 6 macro industries and 21 branches (CVTS3 is not yet available for 21 branches).

- Variable of interest for our estimates:. Cost of CVT courses as a \% of total labour cost (all enterprises).

\section{Estimation method}

Training expenditure $=$ Cost of CVT courses as a \% of total labour cost * Compensation of employees (from National Accounts)

We assume that $100 \%$ of spending is to be considered GFCF.

\section{The estimation method for the years not covered by the survey}

- We have held the share constant for the year before 1999 and we have (linearly) interpolated values for the years between 1999 and 2005.

- We have applied our estimation method at the industry level and then aggregated it to obtain national-level estimates, in order to reflect changes in industry composition.

\section{“Apprenticeships"}




\section{Data source}

Labour Cost Survey (LCS)

- Variable of interest for our estimates:. apprentice costs as a \% of total labor costs.

\section{Estimation method}

Apprenticeships expenditure = apprentice costs as a \% of total labor costs * Compensation of employees (from National Accounts)

We assume that $100 \%$ of spending is to be considered GFCF.

The estimation method for the years not covered by the survey

We have held the share constant

\subsection{New product development costs in the financial services industry}

\section{Data source}

EUKLEMS, WIOD and OECD STAN database.

\section{Estimation method}

The harmonized series of NPD is estimated according to a production cost approach. Based on the evidence reported in Hunt (2008), we assume that most of financial costs of innovation in industry J consist in wages. The main issue here is that data on detailed occupation costs have been compiled for only a few countries can be found only for few countries, one of which is the United States. Therefore, as a first step, we develop a benchmark estimate based on the U.S. data. From these calculations we find that $8 \%$ of compensation of high skilled in industry $J$ is a good approximation for the innovation expenditure in financial industry (see main text). So our estimation proceeds as follows:

First, we calculate labour compensation of high skilled in industry J as:

HSLC_J = (Share in total labour compensation of High-skilled in industry J)*(Total labour compensation industry J)

Then we assume that $8 \%$ of the above expenditure is GFCF based on the evidence for the U.S.. So that:

NFPD_gfcf $=0.08 *$ HSLC_J

\subsection{Software}

\section{Data sources}


Our software estimates are based on three different data sources: the EU KLEMS database, official national accounts data and the use table from the supply and use framework.

The preferred source is EU KLEMS. In the capital input module it provides time series of software investment disaggregated by purchasing industry. Unfortunately, the capital input module is available only for thirteen countries.

For countries not covered by EUKLEMS we resorted to the estimates of software GFCF delivered by National accounts or, when they are not available, to the estimates contained in the use tables: Then we have produced our own estimates of business software (according to the definition of business sector provided in paragraph three). Table 2 below reports the data sources for each of EU27 countries and for Norway.

Estimation method for countries included in the EU KLEMS capital input module

Businees Sector software $g f c f=$ Total economy software gfcf - software gfcf of industries $A, B, L, M, N, P$ and $Q$

Estimation method for countries not included in the EU KLEMS capital input module

Business Sector Employment Share = Employment in industries $C_{-}$to_ $K+O$ / Employment in industries $C_{-}$to_O (from NA)

Business Share EU KLEMS = Business Sector software gfcf (EU KLEMS) / Total Economy software gfcf (EU KLEMS)

Correction Factor (calculated for countries included in EU KLEMS capital input) = Business Share EU KLEMS / Businees Sector Employment Share

Average Correction Factor = arithmetic average of Correction Factor across countries (distinguishing EU15 and New Member States)

Business Sector software $g f f f=$ Business Sector Employment Share * Correction Factor * total software gfcf (from National Accounts)

The only country for which no estimate is available is Cyprus: Statistical Service of Cyprus informed us that no official estimate is available.

Table 2. Data sources for Software GFCF

\begin{tabular}{ll}
\hline Country & Data source \\
\hline Austria & EUKLEMS \\
Belgium & NA \\
Bulgaria & SUT \\
Cyprus & -
\end{tabular}




$\begin{array}{ll}\text { Czech Republic } & \text { EUKLEMS } \\ \text { Denmark } & \text { EUKLEMS } \\ \text { Estonia } & \text { SUT } \\ \text { Finland } & \text { EUKLEMS } \\ \text { France } & \text { EUKLEMS } \\ \text { Germany } & \text { EUKLEMS } \\ \text { Greece } & \text { SUT } \\ \text { Hungary } & \text { NA } \\ \text { Ireland } & \text { NA } \\ \text { Italy } & \text { EUKLEMS } \\ \text { Latvia } & \text { SUT } \\ \text { Lithuania } & \text { SUT } \\ \text { Luxembourg } & \text { SUT } \\ \text { Malta } & \text { SUT } \\ \text { Netherlands } & \text { EUKLEMS } \\ \text { Poland } & \text { SUT } \\ \text { Portugal } & \text { EUKLEMS } \\ \text { Romania } & \text { SUT } \\ \text { Slovakia } & \text { NA } \\ \text { Slovenia } & \text { EUKLEMS } \\ \text { Spain } & \text { EUKLEMS } \\ \text { Sweden } & \text { EUKLEMS } \\ \text { United Kingdom } & \text { EUKLEMS } \\ \text { Norway } & \text { SUT }\end{array}$

Estimation method for the years 2006-2009

We have used data on software gross fixed capital formation from national accounts as an indicator to update Business Sector software gfcf. When available we have used software gfcf by industry to estimate an indicator consistent with our definition of business sector; when industry date are not available we have used total software gfcf (this the case of Belgium, France, Greece, and Luxemburg).

\section{$2.5 R \& D$}

\section{Data source}

Business enterprise expenditures (BERD)

\section{Estimation method}

Expenditure of the computer sector (K72) and the financial intermediation sector (J) are subtracted from the estimate in order to exclude double counting with software and new financial products.

Estimation method for the years 2006-2009 
We have used data on Business enterprise expenditures (BERD) for total economy as an indicator to update estimates for the years 1995-2005.

\subsection{Mineral exploration and Copyright and license costs}

\section{Data sources}

The estimate of GFCF in Mineral exploration and Entertainment, literary and artistic originals is based on two different data sources: official national accounts data when available and the use table from the supply and use framework for the remaining countries. Table 3 reports the data sources for each of EU27 countries and for Norway.

\section{Estimation method}

We assume that all gfcf in Mineral exploration and New motion picture films and other forms of entertainment is performed by firms included in our definition of business sector.

Table 3. Data sources for Mineral exploration and Entertainment, literary and artistic originals GFCF

\begin{tabular}{ll}
\hline Country & Data source \\
\hline Austria & NA \\
Belgium & SUT \\
Bulgaria & SUT \\
Cyprus & - \\
Czech Republic & NA \\
Denmark & NA \\
Estonia & SUT \\
Finland & NA \\
France & NA \\
Germany & SUT \\
Greece & SUT \\
Hungary & NA \\
Ireland & NA \\
Italy & NA \\
Latvia & SUT \\
Lithuania & SUT \\
Luxembourg & SUT \\
Malta & SUT \\
Netherlands & NA \\
Poland & NA
\end{tabular}




$\begin{array}{ll}\text { Portugal } & \text { NA } \\ \text { Romania } & \text { SUT } \\ \text { Slovakia } & \text { NA } \\ \text { Slovenia } & \text { NA } \\ \text { Spain } & \text { SUT } \\ \text { Sweden } & \text { NA } \\ \text { United Kingdom } & \text { NA } \\ \text { Norway } & \text { SUT }\end{array}$

Estimation method for the years 2006-2009

We have used national accounts data on gross fixed capital formation in Mineral exploration and Entertainment, literary and artistic originals as an indicator to update 1995-2005 estimates.

\subsection{New architectural and engineering designs}

The purchased component has been estimated using the nominal gross output of the NACE 2002 version of industry "7420 - Architectural and engineering activities and related technical consultancy".

No countries release national accounts estimates of the gross output of NACE 7420. We try to produce estimates of gross output of industry 7420 consistent with national account data.

\section{$\underline{\text { Data sources }}$}

The data sources are annual, detailed enterprise statistics on services from the Structural Business Statistics (SBS and the Structural Business Statistics on Business Services (SBS_BS).

SBS report data for an aggregate industry that is defines as the sum of NACE7420 and NACE7430 (Technical testing and analysis) while Structural Business Statistics on Business Services report data for the two industries but only for some selected countries and some selected years.

\section{Estimation method}

1. Calculate the share of turnover of industry 7420 in the turnover of industry $7420+7430$ from Structural Business Statistics on Business Services:

NACE7420_share1 = NACE7420_turnover(SBS_BS)

NACE7420+NACE7430_turnover(SBS_BS)

2. Calculate the average share of turnover of industry 7420 in the turnover of industry 7420+7430:

Average_NACE7420_share1 $=$ aritmetic average of NACE7420_share1 (average across countries and years, distinguishing EU15 and New Member States) 
3. Calculate the turnover of industry 7420 from SBS:

NACE7420_turnover $=($ NACE7420 + NACE7430 $) *$ Average_NACE7420_share1.

4. Calculate the share of turnover of industry 7420 in the turnover of industry 74 from SBS data:

NACE7420_share $=$ NACE7420_turnover $/$ NACE74_turnover .

5. Estimate the gross output of NACE 7420 consistent with the national accounts by applying the share to gross output of industry 74 from the national accounts:

NACE7420_output $=$ NACE7420_share * NACE74_output.

6. Estimate the share of turnover of NACE 7420 purchased by the business sector (NACE7420_enterprise_share) from the data disaggregated by client type (information available from both the Structural Business Statistics on Business Services.

7. Estimate the business sector expenditure on New architectural and engineering designs as

design_expenditure $=$ NACE7420_enterprise_share* NACE7420_output.

8. Make an assumption about what proportion of spending is to be considered investment (inv_share). Following Corrado, Hulten and Sichel, we have assumed inv_share $=50 \%$.

According to CHS this share should account also for the New architectural and engineering designs produced on own account.

9. Estimate the value of investment in New architectural and engineering designs (design) by applying the investment share to the total manager's compensation:

design= design_expenditure $*$ inv_share.

Estimation method for the years not covered by the surveys

We have either interpolated NACE7420_share to fill holes between two years or we have it constant to the last value available. Table RR reports, for each country and year, if data from Structural Business Statistics (SBS) are available or not. 
Table RR. Availability of data from Structural business Surveys for NACE 7420

\begin{tabular}{|c|c|c|c|c|c|c|c|c|c|c|c|}
\hline Eurostat $\mathrm{n}$ & 1995 & 1996 & 1997 & 1998 & 1999 & 2000 & 2001 & 2002 & 2003 & 2004 & 2005 \\
\hline Austria & - & - & - & sbs & sbs & sbs & sbs & sbs & sbs & sbs & sbs \\
\hline Belgium & - & - & - & sbs & sbs & sbs & sbs & - & sbs & sbs & sbs \\
\hline Bulgaria & - & - & - & - & - & sbs & sbs & sbs & sbs & sbs & sbs \\
\hline Cyprus & - & - & - & - & - & sbs & sbs & sbs & sbs & sbs & sbs \\
\hline Czech Rer & - & - & - & sbs & sbs & sbs & sbs & sbs & sbs & sbs & sbs \\
\hline Denmark & - & - & - & - & sbs & sbs & sbs & sbs & sbs & sbs & sbs \\
\hline Estonia & - & - & - & - & - & sbs & sbs & sbs & sbs & sbs & sbs \\
\hline Finland & - & - & - & sbs & sbs & sbs & sbs & sbs & sbs & sbs & sbs \\
\hline France & - & - & - & sbs & sbs & sbs & sbs & sbs & sbs & sbs & sbs \\
\hline Germany & - & - & - & - & - & sbs & sbs & sbs & sbs & sbs & sbs \\
\hline Greece & - & - & - & - & sbs & sbs & - & - & sbs & sbs & sbs \\
\hline Hungary & - & - & - & sbs & sbs & sbs & sbs & sbs & sbs & sbs & sbs \\
\hline Ireland & - & - & - & sbs & sbs & sbs & sbs & sbs & sbs & sbs & sbs \\
\hline Italy & - & - & - & sbs & sbs & sbs & sbs & sbs & sbs & sbs & sbs \\
\hline Latvia & - & - & - & sbs & sbs & sbs & sbs & sbs & sbs & sbs & sbs \\
\hline Lithuania & - & - & - & - & - & sbs & sbs & sbs & sbs & sbs & sbs \\
\hline Luxembou & - & - & - & sbs & sbs & sbs & sbs & sbs & sbs & sbs & sbs \\
\hline Malta & - & - & - & - & - & - & sbs & sbs & - & - & - \\
\hline Netherland & - & - & - & sbs & - & sbs & sbs & sbs & sbs & sbs & sbs \\
\hline Poland & - & - & - & sbs & sbs & sbs & sbs & sbs & sbs & sbs & sbs \\
\hline Portugal & - & - & - & sbs & sbs & sbs & sbs & sbs & sbs & sbs & sbs \\
\hline Romania & - & - & - & sbs & sbs & sbs & sbs & sbs & sbs & sbs & sbs \\
\hline Slovakia & - & - & - & - & - & sbs & sbs & sbs & sbs & sbs & sbs \\
\hline Slovenia & - & - & - & - & - & - & - & sbs & sbs & sbs & sbs \\
\hline Spain & - & - & - & - & sbs & sbs & sbs & sbs & sbs & sbs & sbs \\
\hline Sweden & - & - & - & sbs & sbs & sbs & sbs & sbs & sbs & sbs & sbs \\
\hline United Kin & - & - & - & sbs & sbs & sbs & sbs & sbs & sbs & sbs & sbs \\
\hline Norway & - & - & - & - & sbs & sbs & sbs & sbs & sbs & sbs & sbs \\
\hline
\end{tabular}

\section{Estimation method for the years 2006-2009}

For the years 2006-2007 we have replicated the same sources and method we have used to estimate 1995-2005. In the year 2008 there is a break in SBS data: starting from 2008 SBS data are released according to NACE Rev2 classification. For this reason we cannot replicate the same method we have used for the previous years nor using SBS data to calculate an indicator of the change 2008/2007 to estimate 2008. In order to have a consistent indicator of the variation 2008/2007 we have updated NACE7420_turnover and NACE74_turnover using indeces of turnover (of the industry "Architectural and engineering activities; technical testing and analysis" and "Professional, scientific and technical activities required by STS Regulation", respectively). For the year 2009 we have updated design using the change $2009 / 2008$ of the turnover of the industry " Architectural and engineering activities and related technical consultancy" from SBS (Nace Rev2). When SBS data are not available we have estimated the change 2009/2008 from national accounts data on output of the industry "Legal and accounting activities; activities of head offices; management consultancy activities" (Nace Rev2) (Denmark) or from the index of 
turnover of the industry "Architectural and engineering activities; technical testing and analysis" (Greece).

\subsection{Advertising}

\section{Data source}

Zenith Optimedia

\section{Estimation method}

Since the actual expenditure is lower owing to methodological issues within the Zenith Optimedia report compared with the benchmark figures of Haskel et al. (2006) and Edquist (2009), a ratio was calculated and applied to the ZO data, taking the UK and Sweden as references.

\section{Estimation method for the years 2006-2009}

We have updated the estimate of the years 1995-2005 calculating indicators of the change 2006/2005 and 2007/2006 using data on turnover of the Advertising industry from SBS Nace Rev1; of the change 2008/2007 using the index of turnover (of the industry "Advertising and market research"); of the change 2009/2008 using data on turnover of the Avertising industry from SBS Nace Rev2. When SBS data are not available we have estimated the change from national accounts data on output of the industry" Advertising and market research" (Nace Rev2).

\subsection{Market Research}

\section{Data source}

Structural Business Statistics and ESOMAR (European Society for Opinion and Marketing Research)

\section{Estimation method}

Innodrive uses business survey to estimate the share of turnover of NACE 7413 (Market Research) on turnover of NACE 74.

Structural Business Survey data on turnover for NACE7413 have been modified to be consistent with ESOMAR time trends; moreover the spending of the public sector was subtracted from the data by considering public sector consumption as a percentage. 
Then gross output of NACE 7413 consistent with national account is estimated applying the share to gross output of industry 74 from national account (actually from EU KLEMS database, that is assumed to be consistent with national account data).

Finally, gross output of NACE 7413 is doubled to include own-account spending

\section{Estimation method for the years 2006-2009}

We have updated the estimate of the years 1995-2005 calculating indicators of the change 2006/2005 and 2007/2006 using data on turnover of the Market research and public opinion polling industry from SBS Nace Rev1; of the change 2008/2007 using the index of turnover (of the industry " Advertising and market research"); of the change 2009/2008 using data on turnover of the Market research and public opinion polling industry from SBS Nace Rev2. When SBS data are not available we have estimated the change from national accounts data on output of the industry " Advertising and market research" (Nace Rev2). 